\title{
Matrix-Isolation Study and Ab Initio Calculations of the Structure and Spectra of Hydroxyacetone
}

\author{
Archna Sharma, Igor Reva, and Rui Fausto* \\ Department of Chemistry, University of Coimbra, P-3004-535 Coimbra, Portugal
}

Received: February 13, 2008; Revised Manuscript Received: March 27, 2008

\begin{abstract}
The structure of hydroxyacetone (HA) isolated in an argon matrix (at $12 \mathrm{~K}$ ) and in a neat solid phase (at $12-175 \mathrm{~K}$ ) was characterized by using infrared (IR) spectroscopy. The interpretation of the experimental results was supported by high-level quantum chemical calculations, undertaken by using both ab initio (MP2) and density functional theory methods. A potential-energy surface scan, carried out at the MP2/6-311++G(d,p) level of theory, predicted four nonequivalent minima, $\mathrm{Cc}, \mathrm{Tt}, \mathrm{Tg}$, and $\mathrm{Ct}$, all of them doubly degenerate by symmetry. The energy barriers for conversion between most of the symmetrically related structures and also between some of the nonequivalent minima (e.g., $\mathrm{Tg} \rightarrow \mathrm{Tt}$ and $\mathrm{Ct} \rightarrow \mathrm{Tt}$ ) are very small and stay below the zero-point vibrational level associated with the isomerization coordinate in the higher-energy form in each pair. Therefore, only $\mathrm{Cc}$ and $\mathrm{Tt}$ conformers have physical significance, with populations of 99 and 1\%, respectively, in gas phase at room temperature. For the matrix-isolated compound, only the most stable Cc conformer was observed. On the other hand, the polarizable continuum model calculations indicated that in water solution, the population of $\mathrm{Tt}$ and $\mathrm{Ct}$ conformers might be high enough (ca. 6 and 11\%, respectively) to enable their experimental detection, thus supporting the conclusions of a previous IR spectroscopy study [Spectrochim. Acta A 2005, 61, 477] in which the presence of more than one HA conformer in aqueous solution was postulated. The signatures of these minor conformers, however, do not appear in the spectra of the neat HA crystal, and the crystal structure was rationalized in terms of centrosymmetric hydrogen-bonded dimers consisting of two Cc-like units. Finally, we calculated ${ }^{1} \mathrm{H},{ }^{13} \mathrm{C}$, and ${ }^{17} \mathrm{O}$ NMR chemical shifts at different levels of theory and found them to agree with available experimental data.
\end{abstract}

\section{Introduction}

Because of its significant applications in biochemistry, photophysics, photochemistry, and atmospheric chemistry, hydroxyacetone (HA) has received considerable attention. HA is a product of atmospheric reactions, being formed, for instance, during the oxidation of the most important biogenically emitted nonmethane hydrocarbon, isoprene. ${ }^{1}$ Because of this, several investigations focused on the mechanisms of formation of HA, the possible reactions it undergoes in the free and upper troposphere, and the subsequent chemistry. ${ }^{1-8}$

Information about the possible conformers of HA and their populations, as well as their spectroscopic properties, can contribute to a better understanding of the mechanisms of the tropospheric reactions of HA. All studies reported so far for this molecule in the gaseous phase agree about the strong dominance of $\mathrm{Cc}$ conformer (Figure 1) in this phase. ${ }^{1-3,7,9-13}$ Nevertheless, most of them have not excluded the possibility of other conformers to be present as minority species. Microwave studies conducted by Kattija-Ari et al. ${ }^{9}(26-43 \mathrm{GHz}$ region) and Apponi et al. ${ }^{10}$ (4-20 and 65-180 GHz regions) reported $\mathrm{Cc}$ to be the minimum energy conformer of $\mathrm{HA}$, owing to the presence of a strong $\mathrm{O}-\mathrm{H} \cdots \mathrm{O}$ intramolecular hydrogen bond, which also resulted in a low methyl torsional barrier (ca. $65 \mathrm{~cm}^{-1}{ }^{10}$ ) due to the combination of the hyperconjugative effect associated with the methyl and carbonyl groups and the shift of electron density from the latter group to the intramolecular hydrogen bond. ${ }^{9,10}$

* Corresponding author. E-mail: rfausto@ci.uc.pt.

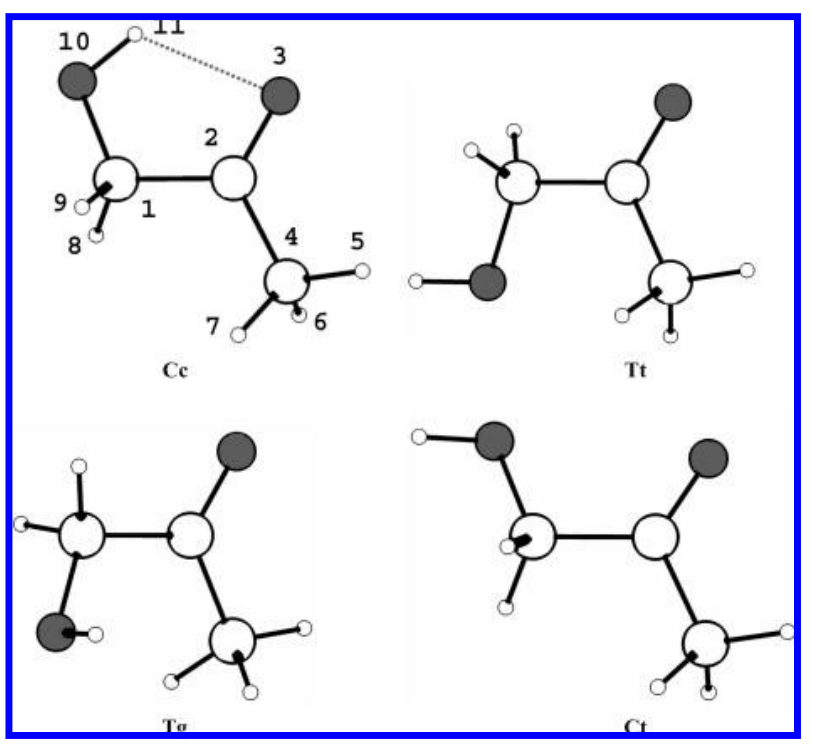

Figure 1. Optimized structures (calculation at the MP2/6-311++G(d,p) level for the monomer in vacuum) of the conformers of HA molecule with atom numbering scheme. In the adopted names of structures $(\mathrm{T}, \mathrm{t}$ $=$ trans; $\mathrm{C}, \mathrm{c}=\mathrm{cis}$; and $\mathrm{g}=$ gauche), the capital letter designates the orientation around the $\mathrm{O}=\mathrm{C}-\mathrm{C}-\mathrm{O}$ dihedral angle, and the small letter refers to the $\mathrm{H}-\mathrm{O}-\mathrm{C}-\mathrm{C}$ dihedral angle. Oxygen atoms are gray.

Mohaček-Grošev ${ }^{11}$ reported the IR spectrum of HA in water solution and claimed the presence of more than one conformer. Such interpretation resulted from the observation in the spectrum of a few bands that could not be assigned to Cc conformer. In that study, however, the author did not characterize precisely 
the minor conformer(s). Jetzki et al. ${ }^{12}$ reported gas- and particlephase spectra of HA and related molecules, suggesting that the dominant conformers in these two phases are different, that is, that aggregation might lead to conversion of the intramolecularly hydrogen-bonded Cc conformer to other conformer(s) where the hydroxyl group is free to take part in intermolecular hydrogen bonds.

In the light of the above facts, it can be concluded that the experimental characterization of the conformational preferences in HA still requires clear elucidation, in particular regarding the gas-phase conformational equilibrium. Matrix-isolation IR spectroscopy then appears to be an adequate method to tackle this problem, because the conformational composition of the HA vapor could in principle be expected to be efficiently trapped in a cryogenic matrix. The identification of different conformers would be facilitated by the high sensitivity of the method to subtle changes in molecular structure, owing to the fact that the spectral resolution afforded by usage of cryogenic inert matrices is considerably higher compared to that of spectroscopy in liquid and solid phases. Moreover, contrarily to gas phase, the matrix-isolated molecules do not rotate in the rigid matrix environment, and the spectra do not contain the complexity originated by rotational contributions. Furthermore, the perturbations due to the inert noble-gas media are minimal, and the experimental spectra can be directly compared to the theoretically calculated data.

Matrix-isolation technique was thus employed in the present study, together with high-level quantum chemical theoretical methods, to obtain more detailed information about the structure, conformational preferences, intramolecular interactions, and spectroscopic properties of the monomeric form of HA. In addition, a spectroscopic investigation of the neat solid state of HA at cryogenic temperatures was also carried out. Finally, quantum chemical calculations for HA in water and chloroform were also undertaken in order to evaluate the influence of the solvent on the stability of conformers. ${ }^{1} \mathrm{H},{ }^{13} \mathrm{C}$, and ${ }^{17} \mathrm{O} \mathrm{NMR}$ chemical shifts for the relevant species of $\mathrm{HA}$ in the same solvents were also calculated by using different theoretical approaches and compared with available experimental data. ${ }^{14,15}$

\section{Experimental Techniques}

HA was obtained from Aldrich (Acetol, Tech., 90\%). Because of its highly hygroscopic nature, the compound was handled in a glovebox to avoid its interaction with atmospheric water. The sample was placed in a glass tube and was then connected to the chamber of the cryostat (APD Cryogenics closed-cycle helium refrigerator with DE-202A expander) through a needle valve (NUPRO SS-4BMRG). The needle valve had two thermostatable parts: the nozzle and the sample compartment. The sample compartment was kept at $-50{ }^{\circ} \mathrm{C}$ (melting 2-pentanol) to provide the compound with adequate vapor pressure. The valve nozzle was kept at room temperature $\left(\sim 25^{\circ} \mathrm{C}\right)$.

Prior to the experiment, the compound was additionally purified by using the standard freeze-pump-thaw technique, and the cell with the compound was further pumped through the cryostat at room temperature to remove volatile impurities. To deposit a matrix, the vapor of HA was introduced into the cryostat chamber through the needle valve, together with large excess of the host matrix gas (Argon N60, Air Liquide) coming from a separate line. A cold CsI window was used as a matrix substrate and was kept at $12 \mathrm{~K}$ during the deposition.

For the experiments carried out on the neat solid states, the compound was deposited as an amorphous layer or a crystalline thin film on the CsI window of the cryostat kept at a temperature of $12 \mathrm{~K}$ (amorphous) or $175 \mathrm{~K}$ (crystal). In both cases, spectra were then collected at different temperatures. The input system used for deposition of the neat crystalline film of HA was the same as the that used for the matrix-isolation experiments, but in this case, no argon was co-deposited. In these experiments, the valve nozzle was also kept at room temperature $\left(\sim 25^{\circ} \mathrm{C}\right)$ during deposition.

IR spectra were recorded with $0.5 \mathrm{~cm}^{-1}$ resolution by using a Mattson (60AR, Infinity series) FTIR spectrometer equipped with a $\mathrm{KBr}$ beamsplitter and a deuterated triglycine sulfate detector.

\section{Computational Methods}

Density functional theory (DFT) and Møller-Plesset to second order (MP2) methods, with the 6-311++G(d,p) basis set $^{16}$ were used to obtain the equilibrium structures of the molecule. In the DFT calculations, the three-parameter hybrid functional abbreviated as B3LYP, which includes Becke's gradient exchange correction ${ }^{17}$ and Lee, Yang, and Parr's ${ }^{18}$ and Vosko, Wilk, and Nusair's ${ }^{19}$ correlation functionals, was used. Because the MP2 method is known in general to give better results for energy calculations, this method was used to perform a complete potential-energy surface (PES) scan for HA. Vibrational spectra calculated for the different minima of HA (Figure 1) were scaled by linear fitting of the calculated wavenumbers to the corresponding experimentally observed values. The obtained scale factors are 0.985 and 0.974 for DFT and MP2, respectively, $(R=0.99974$ and 0.99985 , respectively).

The theoretical normal modes were analyzed by carrying out the potential-energy distribution (PED) calculation. Transformations of the force constants with respect to the Cartesian coordinates to the force constants with respect to the molecule-fixed internal coordinates allowed the normal-coordinate analysis to be performed as described in ref 20. The internal coordinates used in this analysis were defined by following the recommendations of Pulay et al. ${ }^{21}$ The adopted atom numbering scheme is shown in Figure 1, and the symmetry coordinates used in the normal-coordinate analysis are listed in Table 1. Normalized PED matrices were calculated as described in ref 22 .

Polarized continuum model (PCM) calculations, ${ }^{23}$ in the C-PCM (conductor-like PCM) variety, ${ }^{24}$ were carried out for the minimum energy conformations of HA to find their relative stabilities in different solutions. In the C-PCM approach, the solute is placed in a cavity formed by the envelope of spheres centered on the atoms or the atomic groups. Inside the cavity, the dielectric constant is the same as in vacuo; outside, it takes the value of the desired solvent (e.g., $\varepsilon=78.4$ for water and 4.9 for chloroform). The geometries of HA conformers in water and chloroform solutions were fully optimized by using the C-PCM approach at the MP2/6-311++G(d,p) and the DFT(B3LYP)/ $6-311++G(d, p)$ levels. The corresponding vibrational frequencies were calculated numerically. Also, the ${ }^{1} \mathrm{H},{ }^{13} \mathrm{C}$, and ${ }^{17} \mathrm{O}$ NMR spectra of HA in these two solvents were calculated at the MP2 and DFT (B3LYP and BP86 ${ }^{17,25}$ ) levels with the $6-311++\mathrm{G}(\mathrm{d}, \mathrm{p})$ basis set. All quantum chemical calculations were performed by using Gaussian03. ${ }^{26}$

\section{Results and Discussion}

4.1. Minimum Energy Conformations, their Optimized Geometries and Relative Energies, and Barriers to Conformational Isomerization in Vacuum. HA has two main conformationally relevant degrees of freedom related with internal rotation about $\mathrm{C}_{1}-\mathrm{O}_{10}$ and $\mathrm{C}_{1}-\mathrm{C}_{2}$ bonds which may result in several conformers. According to the literature, ${ }^{1-3,7,9-13}$ 
TABLE 1: Symmetry Coordinates Used in the Normal-Mode Analysis for HA

\begin{tabular}{cll}
\hline & \multicolumn{1}{c}{ definition $^{a}$} & approximate \\
coordinate & \multicolumn{1}{c}{ description } \\
\end{tabular}

${ }^{a} \mathrm{r}$, distance between atoms; $\alpha$, bond angle; $\tau$, torsional dihedral angle; $\gamma$, out-of-plane dihedral angle; see Figure 1 for atom numbering. ${ }^{b} v$, stretching; $\delta$, bending; $\tau$, torsion; r, rocking; tw, twisting; w, wagging; as, asymmetric; $s$, symmetric.

one of these conformers is stabilized by an $\mathrm{O}-\mathrm{H} \cdots \mathrm{O}$ intramolecular hydrogen-bond (Cc form; see Figure 1). Most of the previous studies on HA describe this hydrogen-bonded conformer as the most stable one. Initially, the structure of this form was optimized with a $C_{s}$ symmetry at the MP2/6$311++\mathrm{G}(\mathrm{d}, \mathrm{p})$ level. The calculated spectrum of this structure resulted in one imaginary frequency, associated with the torsion of the methyl group. Thus, the optimization was repeated with a $C_{1}$ symmetry and converged to a minimum energy conformation where the $\mathrm{O}=\mathrm{C}-\mathrm{C}-\mathrm{O}, \mathrm{H}-\mathrm{O}-\mathrm{C}-\mathrm{C}$, and $\mathrm{H}-\mathrm{C}-\mathrm{C}=\mathrm{O}$ dihedral angles are $8.2,-11.7$, and $21.8^{\circ}$, respectively (MP2 values). Both MP2/6-311++G(d,p) and DFT(B3LYP)/6-311++G(d,p) methods established that the $\mathrm{Cc}$ form is nonsymmetric and has an isoenergetic, mirrorlike counterpart (with $\mathrm{O}=\mathrm{C}-\mathrm{C}-\mathrm{O}, \mathrm{H}-\mathrm{O}-\mathrm{C}-\mathrm{C}$, and $\mathrm{H}-\mathrm{C}-\mathrm{C}=\mathrm{O}$ dihedral angles equal to $-8.2,11.7$, and $-21.8^{\circ}$, respectively). The $C_{s}$ symmetric structure corresponds to the saddle point on the PES separating these two equivalent-bysymmetry minima.

A PES scan, by using the MP2/6-311++G(d,p) method, was then performed in order to search for additional minima. The $\mathrm{O}=\mathrm{C}-\mathrm{C}-\mathrm{O}$ and $\mathrm{H}-\mathrm{O}-\mathrm{C}-\mathrm{C}$ dihedral angles were incremented in steps of $10^{\circ}$, and all the remaining geometrical parameters were optimized. Figure 2 presents a contour map of the calculated PES. Three additional minima ( $\mathrm{Tt}, \mathrm{Tg}$, and $\mathrm{Ct}$ ) were found on the PES of HA, all of them being doubly degenerate

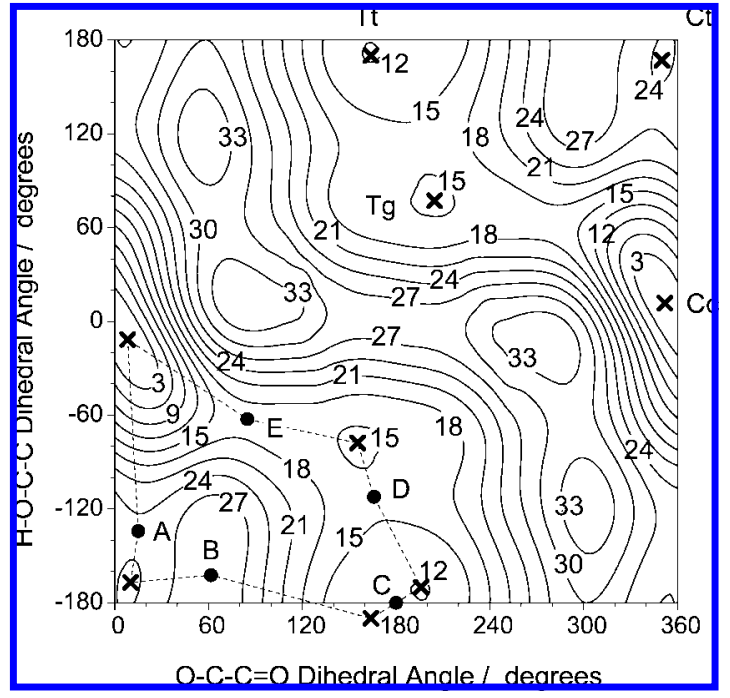

Figure 2. Potential-energy map of HA molecule as a function of internal rotation about the $\mathrm{O}-\mathrm{C}-\mathrm{C}=\mathrm{O}$ and $\mathrm{H}-\mathrm{O}-\mathrm{C}-\mathrm{C}$ dihedral angles. Calculations at the MP2/6-311++G(d,p) level of theory (isolated molecule in vacuum). The two dihedral angles were changed incrementally in steps of $10^{\circ}$, and all the remaining internal coordinates were fully optimized. Minima are indicated in the graph by crosses (x) and labeled ( $\mathrm{Cc}, \mathrm{Ct}, \mathrm{Tt}$, and $\mathrm{Tg}$ ). The first-order saddle points are indicated by black circles and labeled by capital letters $(A-E)$. All forms are doubly degenerate (note that the surface is centrosymmetric). Energies are relative to the most stable conformer (Cc) and do not include zero-point vibrational corrections. Isoenergy levels are spaced by $3 \mathrm{~kJ} \mathrm{~mol}^{-1}$. The dotted lines indicate the lowest-energy paths connecting higher-energy minima $(\mathrm{Ct}, \mathrm{Tt}$, and $\mathrm{Tg}$ ) with the lowestenergy conformer Cc.

by symmetry forms with nonplanar heavy-atom skeleton and belonging to the $C_{1}$ symmetry point group.

Full calculated geometries for the four different energy minima of HA obtained at both the MP2/6-311++G(d,p) and the DFT(B3LYP)/6-311++G(d,p) levels of theory are provided as Supporting Information (Table $\mathrm{S} 1$ ). The $\mathrm{O}=\mathrm{C}-\mathrm{C}-\mathrm{O}$, $\mathrm{H}-\mathrm{O}-\mathrm{C}-\mathrm{C}$, and $\mathrm{H}-\mathrm{C}-\mathrm{C}=\mathrm{O}$ dihedral angles and relative energies (including zero-point-vibrational-energy-corrected energies) for the minima and first-order transition states found on the PES of HA (in vacuum) are given in Table 2. The results obtained with the two calculation methods were found to be similar.

The comparatively low energy of the $\mathrm{Cc}$ form is easy to rationalize in view of the presence of the stabilizing $\mathrm{O}-\mathrm{H} \cdots \mathrm{O}$ intramolecular hydrogen bond, whereas the higher energy of the $\mathrm{Ct}$ form $\left(\Delta E_{\mathrm{ZPVE}}=22.6 \mathrm{~kJ} \mathrm{~mol}{ }^{-1}\right.$; MP2 data $)$ can be attributed to the simultaneous occurrence of the repulsive interactions between the two oxygen atoms in this structure, on one side, and between the face-to-face-oriented methylene and methyl hydrogen atoms, on the other side (see Figure 1). The remaining two minima ( $\mathrm{Tt}$ and $\mathrm{Tg}$ ) have quite similar energies $\left(\Delta E_{\mathrm{ZPVE}}(\mathrm{MP} 2)=11.7\right.$ and $14.2 \mathrm{~kJ} \mathrm{~mol}^{-1}$, respectively $)$, reflecting their close structural similarity. Nevertheless, because of the presence of a repulsive interaction between the hydroxyl hydrogen atom and the methyl group in Tg, this form was found to be slightly less stable than $\mathrm{Tt}$, where such repulsion does not exist (see Figure 1).

In order to identify more precisely the nature of the different conformers of HA, all barriers interconnecting these structures were calculated. Figure 3 shows the MP2 potential-energy profile joining all unique minima on the PES of HA (see the dotted line in the left-bottom corner of Figure 2). In the figure, 
TABLE 2: $D F T / 6-311++G(d, p)$ and MP2/6-311 $++G(d, p)$ Calculated Relevant Dihedral Angles (degree), Relative Energies $\left(\Delta E, \mathrm{~kJ} \mathrm{~mol}^{-1}\right)$, Zero-Point-Vibrational-Energy-Corrected Relative Energies $\left(\Delta E_{\mathrm{ZPVE}}, \mathrm{kJ} \mathrm{mol}^{-1}\right)$, Gibbs Relative Energies at 298 $\mathrm{K}\left(\Delta G_{298}, \mathrm{~kJ} \mathrm{~mol}^{-1}\right)$, Populations at $298 \mathrm{~K}\left(P_{298}, \%\right)$, and Dipole Moments $(\mu$, Debye) for the Minima and First-Order Saddle Points of $\mathrm{HA}$ in the Gas Phase and in Water and $\mathrm{CHCl}_{3}$ Solution (C-PCM Calculations)

\begin{tabular}{|c|c|c|c|c|c|c|c|c|c|c|c|c|c|c|}
\hline \multirow[b]{2}{*}{ conformation } & \multicolumn{2}{|c|}{$\mathrm{OCCO}$} & \multicolumn{2}{|c|}{ HOCC } & \multicolumn{2}{|c|}{$\mathrm{HCCO}$} & \multicolumn{2}{|c|}{$\Delta E$} & \multicolumn{2}{|c|}{$\Delta E_{\mathrm{ZPVE}}$} & \multirow{2}{*}{$\begin{array}{c}\Delta G_{298} \\
\text { MP2 }\end{array}$} & \multirow{2}{*}{$\begin{array}{l}P_{298} \\
\text { MP2 }\end{array}$} & \multicolumn{2}{|c|}{$|\mu|$} \\
\hline & DFT & MP2 & DFT & MP2 & DFT & MP2 & DFT & MP2 & DFT & MP2 & & & DFT & MP2 \\
\hline \multicolumn{15}{|c|}{ Gas Phase } \\
\hline $\mathrm{Tt}$ & 180.0 & 164.0 & 180.0 & 170.0 & 0.0 & 0.9 & 13.7 & 11.9 & 12.6 & 11.7 & 11.2 & 1.1 & 2.9 & 3.4 \\
\hline $\mathrm{Tg}$ & -166.3 & -155.3 & 81.8 & 77.7 & -6.9 & -4.6 & 16.0 & 14.6 & 15.3 & 14.2 & & & 2.2 & 2.2 \\
\hline $\mathrm{Ct}$ & 7.2 & 10.1 & -174.2 & -166.7 & 25.6 & 23.0 & 26.3 & 23.7 & 24.8 & 22.6 & & & 4.6 & 5.1 \\
\hline $\mathrm{Cc} \rightarrow \mathrm{Cc}^{\prime}$ & 0.0 & 0.0 & 0.0 & 0.0 & 0.0 & 0.0 & 0.3 & 0.4 & -0.2 & -0.4 & & & & \\
\hline $\mathrm{Tg} \rightarrow \mathrm{Cc}$ & 84.8 & 84.8 & -63.9 & -62.5 & -4.0 & -3.9 & 4.3 & 2.3 & 5.9 & 3.9 & & & & \\
\hline $\mathrm{Tg} \rightarrow \mathrm{Tg}^{\prime}$ & 180.0 & 161.0 & 0.0 & 3.3 & 0.0 & 5.8 & 12.6 & 13.7 & 11.0 & 12.2 & & & & \\
\hline $\mathrm{Ct} \rightarrow \mathrm{Ct}^{\prime}$ & 0.0 & 0.0 & 180.0 & 180.0 & 0.0 & 0.0 & 0.5 & 0.8 & -0.2 & -0.6 & & & & \\
\hline $\mathrm{Ct} \rightarrow \mathrm{Cc}$ & 13.2 & 15.1 & -138.9 & -134.2 & 22.9 & 21.1 & 0.8 & 0.6 & 0.0 & 0.0 & & & & \\
\hline $\mathrm{Ct} \rightarrow \mathrm{Tt}$ & 63.6 & 61.6 & -174.3 & -162.3 & 1.3 & 1.3 & 8.3 & 5.7 & 3.6 & 8.7 & & & & \\
\hline \multicolumn{15}{|c|}{ In $\mathrm{H}_{2} \mathrm{O}$} \\
\hline $\mathrm{Cc} \rightarrow \mathrm{Cc}^{\prime}$ & 1.3 & 2.2 & 6.1 & 2.7 & 27.2 & 23.2 & 2.0 & 4.2 & 0.6 & 2.5 & & & & \\
\hline $\mathrm{Ct} \rightarrow \mathrm{Ct}^{\prime}$ & 0.0 & 0.6 & 179.8 & -171.7 & -0.1 & -58.3 & 0.5 & 0.9 & -0.1 & -0.3 & & & & \\
\hline $\mathrm{Ct} \rightarrow \mathrm{Cc}$ & 9.2 & 9.9 & -129.9 & -125.5 & 25.5 & 23.1 & 1.9 & 1.6 & 1.1 & 1.1 & & & & \\
\hline $\mathrm{Tt} \rightarrow \mathrm{Tt}^{\prime}$ & & 179.8 & & -179.6 & & 0.0 & & 0.6 & & -0.7 & & & & \\
\hline $\mathrm{Tt} \rightarrow \mathrm{Ct}$ & 73.6 & 69.8 & 175.0 & 177.0 & -3.4 & -1.8 & 13.3 & 10.5 & 14.4 & 10.7 & & & & \\
\hline $\mathrm{Tg} \rightarrow \mathrm{Tt}$ & -167.8 & -161.6 & -128.1 & -119.8 & -1.9 & -3.0 & 2.1 & 1.8 & 0.4 & 0.4 & & & & \\
\hline $\mathrm{Tg} \rightarrow \mathrm{Cc}$ & 79.2 & 79.1 & -69.2 & -67.0 & -3.1 & -2.9 & 9.4 & 7.0 & 10.5 & 7.9 & & & & \\
\hline $\mathrm{Tg} \rightarrow \mathrm{Tg}^{\prime}$ & 163.4 & 148.1 & 5.0 & 8.2 & 3.7 & 7.1 & 22.8 & 23.5 & 21.9 & 23.2 & & & & \\
\hline \multicolumn{15}{|c|}{ In $\mathrm{CHCl}_{3}$} \\
\hline $\mathrm{Cc}$ & 11.5 & 15.0 & -36.0 & -46.3 & 23.0 & 20.6 & $0.0^{i}$ & $0.0^{j}$ & $0.0^{k}$ & $0.0^{l}$ & $0.0^{\circ}$ & 91.4 & 3.7 & 3.5 \\
\hline $\mathrm{Tt}$ & 180.0 & 161.5 & 180.0 & 165.8 & 0.0 & 1.9 & 6.2 & 6.6 & 5.3 & 5.7 & 5.0 & 6.1 & 3.7 & 3.7 \\
\hline $\mathrm{Ct}$ & 5.7 & 7.7 & -175.0 & -168.3 & 28.6 & 24.9 & 9.1 & 9.1 & 8.5 & 8.0 & 7.2 & 2.5 & 5.8 & 5.5 \\
\hline $\mathrm{Ct} \rightarrow \mathrm{Tt}$ & 71.7 & 67.8 & -177.1 & -176.2 & -1.9 & -0.6 & 12.4 & 9.8 & 12.9 & 10.3 & & & & \\
\hline
\end{tabular}

${ }^{a}-704837.91 \mathrm{~kJ} \mathrm{~mol}^{-1}{ }^{b}-702925.97 \mathrm{~kJ} \mathrm{~mol}^{-1}{ }^{c}{ }^{c}-704604.98 \mathrm{~kJ} \mathrm{~mol}^{-1}{ }^{d}-702689.60 \mathrm{~kJ} \mathrm{~mol}^{-1} .{ }^{e}-704873.61 \mathrm{~kJ} \mathrm{~mol}^{-1} . f-702960.65 \mathrm{~kJ}^{f}$ $\mathrm{mol}^{-1} .{ }^{g}-704644.02 \mathrm{~kJ} \mathrm{~mol}^{-1} \cdot{ }^{h}-702726.56 \mathrm{~kJ} \mathrm{~mol}^{-1} \cdot{ }^{i}-704863.81 \mathrm{~kJ} \mathrm{~mol}^{-1} \cdot{ }^{j}-702951.31 \mathrm{~kJ} \mathrm{~mol}^{-1} \cdot{ }^{k}-704633.85 \mathrm{~kJ}^{-1} \mathrm{~mol}^{-1} \cdot{ }^{l}-702716.74$ $\mathrm{kJ} \mathrm{mol}^{-1} .^{m}-702766.88 \mathrm{~kJ} \mathrm{~mol}^{-1} .^{n}-702803.46 \mathrm{~kJ} \mathrm{~mol}^{-1}{ }^{o}-702793.73 \mathrm{~kJ} \mathrm{~mol}^{-1}$.

note the changes of the reaction coordinates indicated by the vertical dashed lines. Horizontal thin lines indicate the position of the lowest vibrational level associated with the reaction coordinate connecting a given minimum with the others. The positions of these vibrational levels were determined from the MP2 calculated vibrational frequencies (see Table 3 and Table S2 in the Supporting Information).

As seen in Figure 3, there are several interconnecting saddle points between minima on the PES of HA that have energies below the zero vibrational level $\left(v_{0}\right)$ of at least one of the species they interconnect. This happens for saddle points A, C, and D associated with the $\mathrm{Ct} \rightarrow \mathrm{Cc}\left[\Delta E_{\mathrm{A}-\mathrm{Ct}}=0.64 \mathrm{~kJ} \mathrm{~mol}^{-1}\right.$; $\left.v_{0}(\tau \mathrm{O}-\mathrm{C})_{\mathrm{Ct}}=1.11 \mathrm{~kJ} \mathrm{~mol}^{-1}\right], \mathrm{Tt} \rightarrow \mathrm{Tt}^{\prime}\left\{\Delta E_{\mathrm{C}-\mathrm{Tt}}=0.37 \mathrm{~kJ}\right.$ $\left.\mathrm{mol}^{-1} ; v_{0}[\tau \mathrm{C}-\mathrm{C}(=\mathrm{O})]_{\mathrm{Tt}}=0.37 \mathrm{~kJ} \mathrm{~mol}^{-1}\right\}$, and $\mathrm{Tg} \rightarrow \mathrm{Tt}$ $\left[\Delta E_{\mathrm{D}-\mathrm{Tg}}=0.77 \mathrm{~kJ} \mathrm{~mol}^{-1} ; v_{0}(\tau \mathrm{O}-\mathrm{C})_{\mathrm{Tg}}=1.41 \mathrm{~kJ} \mathrm{~mol}^{-1}\right]$ processes but also for the saddle points associated with the $\mathrm{Cc} \rightarrow \mathrm{Cc}^{\prime}$ and the $\mathrm{Ct} \rightarrow \mathrm{Ct}^{\prime}$ interconversions that are not represented in Figure 3 [the relative energies of these two saddle points are 0.42 and $0.75 \mathrm{~kJ} \mathrm{~mol}^{-1}$, respectively, which shall be compared with the MP2 calculated energies for the zero-point vibrational levels associated with the relevant torsional coordinates, $\tau \mathrm{C}-\mathrm{C}\left(\mathrm{H}_{3}\right)$ in both cases, in $\mathrm{Cc}$ and $\mathrm{Ct}$, which are 0.54 and $0.73 \mathrm{~kJ} \mathrm{~mol}^{-1}$, respectively].

There are two main consequences that can be extracted from what has been mentioned above: (i) both the $\mathrm{Ct}$ and $\mathrm{Tg}$ minima (and also their corresponding symmetry-related forms, $\mathrm{Ct}^{\prime}$ and $\mathrm{Tg}^{\prime}$ ) cannot be considered as real conformers but are better described as high vibrational excited states of $\mathrm{Cc}$ and $\mathrm{Tt}$ forms, respectively and (ii) the two pairs of symmetry-related shallow minima, $\mathrm{Cc} / \mathrm{Cc}^{\prime}$ and $\mathrm{Tt} / \mathrm{Tt}^{\prime}$, shall be effectively considered as the only two conformers (for simplicity, we will designate these conformers as $\mathrm{Cc}$ and $\mathrm{Tt}$ ) the most probable geometries of which correspond to the symmetric structures (saddle points) between the two equivalent minima for each case. The same conclusions can be extracted from the relative energy differences between the saddle points which connect the different minima when zeropoint vibrational energies are taken into account $\left(\Delta E_{\mathrm{ZPVE}}\right)$. In Table 2, whenever $\Delta E_{\mathrm{ZPVE}}$ associated with a conversion from 


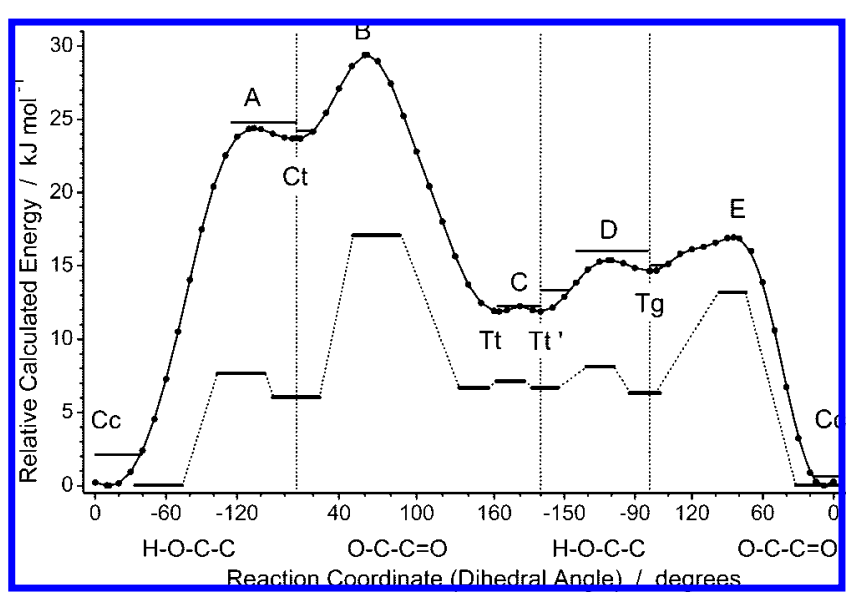

Figure 3. Potential-energy curve (solid line): the lowest-energy path connecting higher energy minima $(\mathrm{Ct}, \mathrm{Tg}$, and $\mathrm{Tt}$ and its mirror image $\mathrm{Tt}^{\prime}$ ) with the lowest-energy conformer Cc, calculated at the MP2/6$311++G(d, p)$ level of theory (isolated molecule in vacuum). This path corresponds to the dotted line in Figure 2. Note the changes of the reaction coordinates indicated by the vertical dashed lines. The linear scale was chosen to be the same for different reaction coordinates. Capital letters A-E designate the first-order saddle points. Energies are relative to the most stable conformer $(\mathrm{Cc})$ and do not include zeropoint vibrational corrections. The zero-point vibrational levels of the relevant vibrational coordinates are shown as horizontal lines over the associated minima and saddle points. Energy-levels diagram: relative energies (without zero-point energy corrections) of minima and saddle points for HA in water solution, calculated by using the C-PCM approach at the same theory level. The relative zero level was chosen to be equal to the energy of $\mathrm{Cc}$ conformer.

one energy minimum on the PES into another one of lower energy is negative, this means that the zero-point-corrected energy of the saddle point is below that of the higher-energy minimum; therefore, this minimum does not have any practical significance. Obviously, in the case of interconversions between symmetrically related minima, the zero-point-corrected energy of the saddle point is below that of both minima that it interconnects, and this structure then corresponds to the most probable structure defining the geometry of the sole conformer associated with the two symmetry-related minima.

The remaining barriers between minima on the PES were found to range from high to moderately low. The interconnecting $\mathrm{Tg} / \mathrm{Tg}^{\prime}$ (not shown in Figure 3) is as large as $13.7 \mathrm{~kJ} \mathrm{~mol}^{-1}$ because in the transition state, the hydroxyl hydrogen atom interacts strongly with the methyl group. On the other hand, the barriers separating $\mathrm{Ct}$ from $\mathrm{Tt}$ and $\mathrm{Tg}$ from $\mathrm{Cc}$ along the $\mathrm{O}=\mathrm{C}-\mathrm{C}-\mathrm{O}$ torsional coordinate, as well as the global barrier for the $\mathrm{Tt} \rightarrow \mathrm{Cc}$ isomerization $\left(5.8 \mathrm{~kJ} \mathrm{~mol}^{-1}\right)$, are moderately low (5.7 and $2.3 \mathrm{~kJ} \mathrm{~mol}^{-1}$, respectively).

In the context of the present matrix-isolation study, all this information regarding energy barriers is of great relevance, because during deposition of cryogenic inert matrices, most of the time, low-energy barriers (a few $\mathrm{kJ} \mathrm{mol}^{-1}$ ) can be surpassed, leading to relaxation of higher-energy conformers to lowerenergy forms. ${ }^{27,28}$ As pointed out above, for HA, besides Cc conformer, only conformer Tt represents a true conformational state which could in principle be projected to have a nonvanishing probability to be trapped in the matrices and to be experimentally observed in the as-deposited matrix. Nevertheless, it shall be noticed that the global barrier for the $\mathrm{Tt} \rightarrow \mathrm{Cc}$ isomerization $\left(5.8 \mathrm{~kJ} \mathrm{~mol}^{-1}\right)$ is still in the range of values 27,28 that can be expected to be low enough to allow for conformational cooling to take place during deposition.

4.2. Matrix-Isolation FT-IR Studies. From the relative Gibbs energies of $\mathrm{Cc}$ and $\mathrm{Tt}$ conformers of HA at the reference temperature (temperature of the vapor of the compound immediately prior to deposition, $298.15 \mathrm{~K}\left(25^{\circ} \mathrm{C}\right)$ ) calculated at the MP2 level, the relative populations of the two conformers in the gaseous phase before deposition could be easily estimated by using the Boltzmann distribution, $\mathrm{Cc}: \mathrm{Tt}=99: 1$; that is, the calculations predict the most stable Cc conformer as strongly dominating in the gas phase at room temperature.

Figure 4 presents the spectrum of HA in argon matrix $(T=$ $12 \mathrm{~K}$ ), prepared from the vapor of the compound at $25^{\circ} \mathrm{C}$. A detailed analysis of the experimental spectra, for the originally deposited sample (at $12 \mathrm{~K}$ ) and after its annealing (up to 34 $\mathrm{K})$, doubtlessly demonstrated that only the Cc conformer is present in the matrix. In particular, the vibrations of the $\mathrm{OH}$ group are very sensitive to the molecular conformation, and no bands appear in the experimental spectrum around 3650 and $1175 \mathrm{~cm}^{-1}$, where the strong absorptions due to the $v \mathrm{OH}$ and the $\delta \mathrm{COH}$ modes of the nonhydrogen-bonded $\mathrm{OH}$ group of $\mathrm{Tt}$ conformer would be expected. Moreover, the whole experimental spectrum below $1500 \mathrm{~cm}^{-1}$ is in much better agreement with the calculated spectrum of the Cc form compared with that of the Tt form. In Figure 4, the experimental spectrum is compared with the MP2/6-311++G(d,p) calculated spectra for conformers $\mathrm{Cc}$ and $\mathrm{Tt}$ (calculated spectra for all four minima on the PES of HA are provided in the Supporting Information, Figure S1).

There are two main reasons justifying the nonobservation of any spectral feature ascribable to the $\mathrm{Tt}$ form in the experimental spectrum: (i) the small population of this form in the gas phase at $25{ }^{\circ} \mathrm{C}(1 \%)$ is of the order of magnitude of the limit of detection of the method (in general a few $\%$, depending on the similarity of the spectra of different forms in the regions where the most intense vibrations are predicted to occur) and (ii) as mentioned above, it is also possible that the $\mathrm{Tt}$ form can have its population reduced even more because of its conversion to the most stable Cc conformer during deposition of the matrix because the barrier for this conversion (see Figure 3) is still low enough to have a nonvanishing probability to be overcome at this occasion.

The advantage of having only one conformer in the prepared matrices is that its vibrational characterization could be done in deep detail, as discussed below. Nevertheless, we tried also to populate the Tt conformer in order to study it spectroscopically too. At first thought, one possibility to achieve this goal would be increasing the temperature of the vapor of the compound before deposition. However, taking into account the relative energies of the two conformers, it can be easily concluded that increasing the temperature of the vapor prior to deposition up to the maximum temperature accessible to our setup (ca. $180{ }^{\circ} \mathrm{C}$ ) would lead only to very small population changes in the gas phase (ca. $4 \%$, assuming also that no decomposition of the compound would occur), which would be already near the detection limit of the method. Moreover, because the partial isomerization due to conformational cooling is expected to take place during deposition, the hotter the sample being deposited, the greater the importance of this effect. That is why the effective population changes due to the increase of the gas temperature prior to deposition would be negligible in practical terms. Then, in order to populate the highest-energy conformer, alternative possibilities were tried: irradiation of the as-deposited matrix with UV light (from a $500 \mathrm{~W} \mathrm{Hg}(\mathrm{Xe})$ lamp, Newport, Oriel Instruments, set to provide an output of 200 W) and also IR irradiation (by means of a kanthal wire heated to orange glowing). Neither irradiation experiment, however, 
TABLE 3: Observed (FTIR, Argon Matrix at $12 \mathrm{~K}$ ) and Calculated (DFT and MP2, Isolated Molecule in Vacuum) Vibrational Frequencies (freq., $\left.\mathrm{cm}^{-1}\right)$, IR Intensities $\left(\mathrm{km} \mathrm{mol}^{-1}\right)$, and Vibrational Assignments (PEDs, \%) for HA Monomer (Cc Conformer)

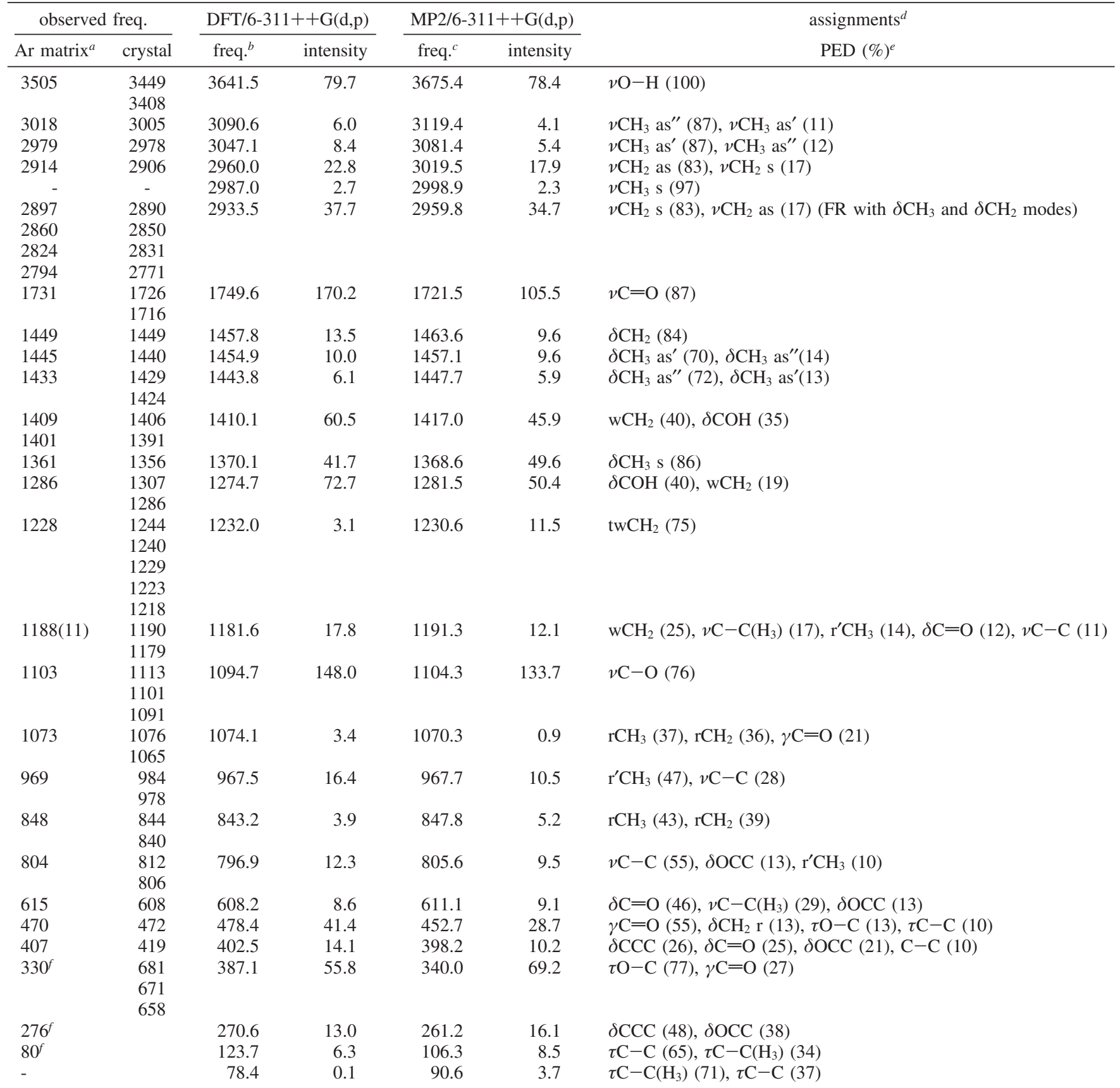

${ }^{a}$ The xperimental range below $400 \mathrm{~cm}^{-1}$ was not accessible in the present study. ${ }^{b}$ DFT frequencies were scaled with a factor of 0.985 . ${ }^{c}$ MP2 frequencies were scaled with a factor of $0.974 .{ }^{d} v$, stretching; $\delta$, bending; r, rocking; tw, twisting; w, wagging; $\gamma$, out of plane; $\tau$, torsion; as, asymmetric; s, symmetric. ${ }^{e}$ PEDs (in parentheses) correspond to the MP2 calculations. Contributions less than $10 \%$ were omitted. ${ }^{f}$ Raman, neat liquid. ${ }^{11}$

led to any spectral changes that could be attributed to an increase of the population of a higher-energy conformer.

IR pumping has been used successfully to promote conformational isomerization in matrix-isolated molecules exhibiting structural similarities to HA, such as, for instance, acetic, propionic, and glycolic acids. ${ }^{29-34}$ In all these cases, excitation of the $\mathrm{OH}$ stretching mode (either the fundamental vibration or the first overtone) has been carried out in the initial reaction step. ${ }^{29-34}$ Following this initial step, vibrational relaxation from the excited coordinate into the low frequency torsional reactive coordinate takes place through a series of processes in cascade involving different vibrational states of the reactant species, which might be assisted by the lattice to compensate the energy mismatch between the intramolecular energy levels involved in the energy relaxation, converting the excess internal energy of the guest molecule into lattice phonons. ${ }^{35,36}$ It has been suggested that in order to be efficient, this relaxation mechanism requires a low density of low-energy states to prevent competition between the reactive channels and the nonreactive energydissipation channels. ${ }^{29,34}$ For example, the observed one order of magnitude reduction in the quantum yields for trans-to-cis conversion in acetic acid when compared to formic acid has been shown to be due to the presence of the additional methyl group and the associated nonreactive low-frequency methyl torsional mode ${ }^{29,32}$ in acetic acid. Thus, in the case of HA, the inefficiency of the IR pumping in promoting conversion from 


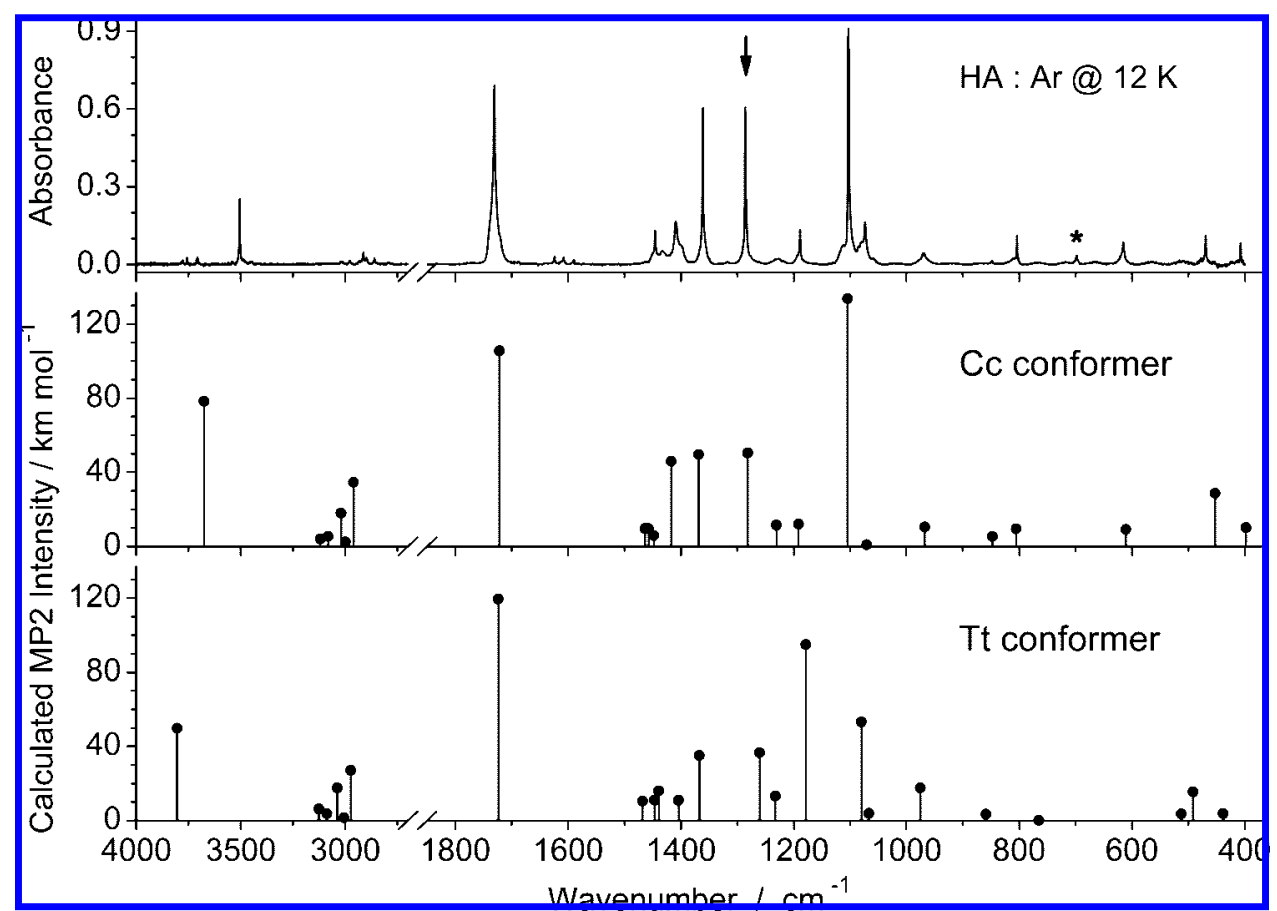

Figure 4. Experimental FTIR spectrum of HA monomers isolated in an argon matrix at $12 \mathrm{~K}$ (top) and theoretically calculated (at the MP2/6$311++\mathrm{G}(\mathrm{d}, \mathrm{p})$ level, for the isolated molecule in vacuum) IR spectrum of the most stable Cc conformer (middle) and a minor Tt form (bottom). The calculated frequencies were scaled by a factor of 0.974 (obtained by a least-squares linear fit in the fingerprint region). In the experimental spectrum, the band at $698 \mathrm{~cm}^{-1}$ (marked by an asterisk) does not have a calculated counterpart and was assigned to the first overtone of the $\tau \mathrm{O}-\mathrm{C}$ fundamental. The band at $1286 \mathrm{~cm}^{-1}$ (marked by an arrow) disappears upon transition from monomeric to the aggregated HA (see text for details) and was assigned to the $\delta \mathrm{COH}$ fundamental of $\mathrm{Cc}$ conformer.

Cc into Tt can be attributed, in a way similar to that in acetic acid, to the quenching of the relaxation processes involving the reactive coordinates ( $\tau \mathrm{O}-\mathrm{C}$ and $\tau \mathrm{C}-\mathrm{C}$ ) due to competition with those involving the lowest-frequency methyl torsional mode $\left(\tau \mathrm{C}-\mathrm{C}\left(\mathrm{H}_{3}\right)\right)$. An alternative explanation for the observed inactivity of the IR pumping in HA is that in the present experiments, a broadband IR irradiation was used. Therefore, the simultaneous occurrence of both direct and inverse isomerization reactions, with the latter (where Cc appears as the product) being more efficient than the former, cannot be excluded. To verify this possibility, experiments involving narrow-band selective pumping of the $\mathrm{Cc}$ conformer are required. Of course, it is also possible that the higher-energy form could just quickly relax radiationlessly to the most stable form, either over the barrier (because, as already mentioned, the energy barrier is small) or by tunneling (as, for instance, was observed previously for matrix-isolated formic, acetic, and propionic acids). ${ }^{30,32,34}$ Narrow-band selective IR pumping experiments may also shed some light on the relevance of these putative relaxation mechanisms.

As mentioned before, the detailed assignment of the matrix isolation IR spectrum of $\mathrm{Cc}$ conformer was facilitated by the sole presence of this conformer in the matrix. The assignments are presented in Table 3, together with the results of the theoretical calculations and normal-coordinate analysis.

A comparison of the experimental and calculated spectra (Figure 4) reveals that these spectra are similar regarding both the position and the intensity of the bands. The spectra are dominated by five intense bands at 3505, 1731, 1361, 1286, and $1103 \mathrm{~cm}^{-1}$, which were assigned to $\nu \mathrm{OH}, \nu \mathrm{C}=\mathrm{O}, \delta \mathrm{CH}_{3} \mathrm{~s}$, $\delta \mathrm{COH}$, and $\nu \mathrm{C}-\mathrm{O}$, respectively [MP2 calculated (scaled) frequencies: $3675.4,1721.5,1368.6,1281.5$, and $1104.3 \mathrm{~cm}^{-1}$; see Table 3]. The theoretical calculations predicted also a sixth intense mode, with dominant contribution from the $\mathrm{wCH}_{2}$ wagging coordinate, which should give rise to a band at ca. $1417 \mathrm{~cm}^{-1}$. In the experimental spectrum of the matrix-isolated compound, this vibration is observed as a doublet at 1401 and $1409 \mathrm{~cm}^{-1}$, the observed splitting being probably due to the Fermi-resonance interaction between this mode and the $804+$ $615 \mathrm{~cm}^{-1}$ combination tone.

The assignment of the less intense bands was also straightforward (Table 3). Because we did not investigate the frequency region below $400 \mathrm{~cm}^{-1}$, the calculated vibrational bands in this region are compared in Table 3 with those reported by MohačekGrošev ${ }^{11}$ for liquid HA (Raman spectrum). This author assigned a broad band at $\sim 80 \mathrm{~cm}^{-1}$ in the Raman spectrum of liquid HA to the hydroxymethyl internal rotation and the weak Raman band at $330 \mathrm{~cm}^{-1}$ to the $\tau \mathrm{O}-\mathrm{C}$ torsional mode. These frequencies are similar to the MP2 calculated values now obtained: 106.3 and $340.0 \mathrm{~cm}^{-1}$, respectively (see Table 3 ). An additional low-frequency band was observed at $276 \mathrm{~cm}^{-1}$ in the Raman spectrum of liquid $\mathrm{HA},{ }^{11}$ which corresponds to a skeletal vibration with large contribution of OCC and CCC bending coordinates. The MP2 calculated value $261.2 \mathrm{~cm}^{-1}$ is in very good agreement with the experimental data. Very unfortunately, no experimental frequency for the $\tau \mathrm{C}-\mathrm{C}\left(\mathrm{H}_{3}\right)$ mode has been reported yet [the calculated intensity for this mode, as predicted by the MP2 method, is very low $\left.\left(4.7 \mathrm{~km} \mathrm{~mol}^{-1}\right)\right]$, preventing any comparison with the calculated value, $90.6 \mathrm{~cm}^{-1}$ (see Table 3).

The weak band observed at $698 \mathrm{~cm}^{-1}$ also deserves here a brief comment because no $\mathrm{Cc}$ fundamental band is predicted by the calculations around this frequency (see Table 3). This band, very probably, is due to the first overtone of the $\tau \mathrm{O}-\mathrm{C}$ vibration. According to this assignment, such band is absent in the spectrum of crystalline HA (discussed later in this paper). Because of crystal packing and strengthening of hydrogen-bond interactions in this phase, as expected, the $\tau \mathrm{O}-\mathrm{C}$ fundamental 
vibration shifts to a considerably higher frequency (from ca. 330-340 to ca. $660 \mathrm{~cm}^{-1}$ ).

4.3. Solvent Effects on the Conformational Equilibria. As mentioned in the Introduction, Mohaček-Grošev ${ }^{11}$ postulated the existence of at least one additional minor conformer of HA in water solution, on the basis of the observation in the corresponding IR spectra of three bands (at 1057, 552, and $465 \mathrm{~cm}^{-1}$ ) which could not be assigned to the $\mathrm{Cc}$ conformer. In order to examine this possibility, we performed additional theoretical conformational studies for HA in water solution. The obtained data are summarized in Table 2 and Figure 3.

According to both MP2 and DFT calculations, all four minima $(\mathrm{Cc}, \mathrm{Tt}, \mathrm{Tg}$, and $\mathrm{Ct}$ ) found for the isolated molecule exist on the PES of HA in water solution. As in the gas phase, the $\mathrm{Cc}$ conformer remains the global energy minimum in water. Unlike in the gas phase, the $\mathrm{CCOH}$ dihedral angle in this most stable conformer assumes a $g$ orientation (the MP2 calculated value in water environment is $54.6^{\circ}$ ). Strictly speaking, such a form should have another name $(\mathrm{Cg})$, but for uniformity, we shall continue to call the most stable structure in water also Cc. An important consequence is that the most stable conformer in water will become doubly degenerate by symmetry $\left(\mathrm{Cg}\right.$ and $\left.\mathrm{Cg}^{\prime}\right)$. As it will be shown below, the polarizable environment (without explicitly present hydrogen bonds) results in the same change of geometry as that that would be imposed on the structure of the main conformer by the presence of intermolecular hydrogen bonding (i.e., in hydrogen-bonded dimers).

Regarding C-PCM calculations in water, the relative energies of the remaining minima in this medium were found to be much lower when compared to the gas phase (Figure 3). The stabilization of $\mathrm{Ct}$ conformer is particularly large, in agreement with its large dipole moment $(6.8 \mathrm{D}$ in water, as predicted by the MP2 calculations; all the other conformers have predicted dipole moments lower than $5 \mathrm{D}$, see Table 2). Very interestingly, the two higher-energy forms ( $\mathrm{Tg}$ and $\mathrm{Tt}$ ) are predicted to have similar energies in water environment, the $\mathrm{Tt}$ form being more stable after accounting for the zero-point vibrational energy (see Table 2). The barrier for conformational interconversion $\mathrm{Tg} \rightarrow \mathrm{Tt}$ was found to lie below the ground-state vibrational level of the reaction coordinate ( $\mathrm{OH}$ torsion) separating these two forms. Then, as for the molecule in vacuum, the Tg form becomes irrelevant in water solution.

The calculations performed for water solution showed that the barrier for conformational interconversion $\mathrm{Ct} \rightarrow \mathrm{Cc}$ is large enough, making the $\mathrm{Ct}$ minimum relevant in practical terms. The saddle points associated with the $\mathrm{Ct} \rightarrow \mathrm{Ct}^{\prime}$ and $\mathrm{Tt} \rightarrow \mathrm{Tt}^{\prime}$ interconversions have zero-point-corrected energies below those of the two equivalent minima they connect (see Table 2). Hence, $\mathrm{Ct}$ and $\mathrm{Tt}$ correspond to singly degenerate conformers (with their most probable structures corresponding to the associated saddle points for interconversion between the two equivalentby-symmetry minima on the PES), whereas Cc conformer is doubly degenerate. The calculated populations for the different conformers at $25{ }^{\circ} \mathrm{C}$ relate then as $\mathrm{Cc}: \mathrm{Ct}: \mathrm{Tt}=83.2: 11.0: 5.8$; that is, the present theoretical results sustain the proposition of Mohaček-Grošev ${ }^{11}$ regarding the existence of more than one conformer of HA in water solution. Considering the predicted relative populations for the various conformers, one can expect that $\mathrm{Ct}$ and $\mathrm{Tt}$ forms should give rise to observable features in the IR spectra of the compound in water solution.

The calculated vibrational frequencies (and IR intensities) for $\mathrm{Cc}, \mathrm{Ct}$, and $\mathrm{Tt}$ conformers in aqueous solution are provided in Table 4, together with the IR frequencies reported by MohačekGrošev. ${ }^{11}$ According to the calculated data, the IR bands observed at 465,580 , and $750 \mathrm{~cm}^{-1} 11$ correspond to the $\gamma \mathrm{C}=\mathrm{O}$, $\delta \mathrm{C}=\mathrm{O}$, and $\nu \mathrm{C}-\mathrm{C}$ modes of the $\mathrm{Ct}$ conformer (predicted at 452,598 , and $796 \mathrm{~cm}^{-1}$, respectively), whereas that observed at $503 \mathrm{~cm}^{-11}$ corresponds to the $\delta \mathrm{C}=\mathrm{O}$ mode of the $\mathrm{Tt}$ conformer (MP2 predicted value, $494 \mathrm{~cm}^{-1}$ ). In addition, the experimental bands at 841 and $1287 \mathrm{~cm}^{-1}$ are also only due to the two higher-energy forms, corresponding to the highly mixed bending $\mathrm{CH}_{2}$ modes (calculated at 853 and $1265 \mathrm{~cm}^{-1}$ in $\mathrm{Tt}$ and 845 and $1254 \mathrm{~cm}^{-1}$ in $\mathrm{Ct}$ ), which are predicted to occur at considerably lower frequencies in the most stable Cc conformer and are assigned to the bands at 816 and $1211 \mathrm{~cm}^{-1}$ (see Table 4).

4.4. Low-Temperature Spectrum of Neat Crystalline HA. As mentioned in the Introduction, Jetzki et al. ${ }^{12}$ observed that the band at $1288 \mathrm{~cm}^{-1}$ present in the experimental spectra of gaseous HA was missing in the particle spectrum. Therefore, it was concluded $^{12}$ that the particles consist predominantly of the open forms of the compound ( $\mathrm{Ct}$ and $\mathrm{Tt}$ in the present notation), where the hydroxyl group is free to take part in intermolecular hydrogen bonds. The fact that in water solution, conformers $\mathrm{Tt}$ and $\mathrm{Ct}$ are observed experimentally ${ }^{11}$ could also be considered as pointing in the same direction.

In the present study, we obtained the amorphous solid state of HA, produced by fast deposition of the vapor of the compound onto the cold $(12 \mathrm{~K}) \mathrm{CsI}$ window of the cryostat. This spectrum is presented in Figure 5 (trace A) and is identical to the particle spectra (recorded at $78 \mathrm{~K}$ ) obtained by Jetzki et al. ${ }^{12}$ The crystalline phase of the compound was also obtained in the present study. It was produced directly by deposition of HA vapor onto the cryostat window at $175 \mathrm{~K}$ or, alternatively, by continued annealing of the previously produced amorphous solid up to this temperature. Figure 5 (trace B) shows the experimental IR spectrum of the neat crystal at $12 \mathrm{~K}$. Unlike the intense band at $1288 \mathrm{~cm}^{-1}$ found in the spectrum of the gaseous phase ${ }^{12}$ or the band at $1286 \mathrm{~cm}^{-1}$ in argon matrix (Figure 4) and assigned to the $\delta \mathrm{COH}$ vibration of the $\mathrm{Cc}$ conformer, neither the spectrum of our amorphous sample nor the spectrum of the crystal contains bands around $1288 \mathrm{~cm}^{-1}$. The nonobservation of such band was interpreted in ref 12 in terms of two statements. Their first statement was that at least a partial breakup of the intramolecular hydrogen bond occurs in conformer $\mathrm{Cc}$ (ZZ in their notation) upon aggregation. Their second statement was based on the first one and read that the particles (aggregates) consisted of open forms of the compound (such as $\mathrm{Ct}$ or $\mathrm{Tt}$ ).

To verify these statements, we analyzed additional experimental results that were not available at the time of publication of ref 12. These new experimental results include our experimental spectra of HA crystal (Figure 5) and experimental spectra of Mohaček-Grošev ${ }^{11}$ for HA in solutions. Surprisingly, no bands were observed in the spectra of crystals at the positions where the bands originated in $\mathrm{Ct}$ and $\mathrm{Tt}$ conformers were reported for HA in water solution ${ }^{11}$ (e.g., at 503, 580, and 750 $\mathrm{cm}^{-1}$; see Table 4). Thus, the interpretation of the structure of HA aggregates in terms of the open forms (the second statement of Jetzki et al.) should be revised to satisfy the new experimental facts.

To suggest an alternative explanation, we explored structure motifs for HA aggregates which would not involve conformers other than $\mathrm{Cc}$ and simulated their IR spectra. Many dimer structures similar in energy were obtained, and their IR spectra were calculated. A plausible explanation for the changes in the experimental spectra could be obtained by using a centrosymmetric HA dimer constructed of two Cc conformers depicted 
TABLE 4: MP2/6-311++G(d,p) Calculated Frequencies $\left(v, \mathrm{~cm}^{-1}\right.$, scaled by 0.974) and IR Intensities $\left(\mathrm{I}, \mathrm{km} \mathrm{mol}^{-1}\right) \mathrm{for} \mathrm{Cc}^{\mathrm{Ct}} \mathrm{Ct}$ and Tt Conformers of HA (C-PCM Calculations in Water) and IR Experimental data ${ }^{11}$ for HA in Water Solution ${ }^{a}$

\begin{tabular}{|c|c|c|c|c|c|c|c|c|}
\hline \multicolumn{2}{|c|}{$\mathrm{Cc}$} & \multicolumn{2}{|c|}{$\mathrm{Tt}$} & \multicolumn{2}{|c|}{$\mathrm{Ct}$} & \multicolumn{2}{|c|}{ exptl. ${ }^{11}$} & \\
\hline$v$ & $I$ & $v$ & $I$ & $v$ & $I$ & $v$ & $I^{b}$ & \\
\hline 101.7 & 0.2 & 156.1 & 12.2 & 96.5 & 1.2 & n. inv. & & $\tau \mathrm{C}-\mathrm{C}\left(\mathrm{H}_{3}\right)$ \\
\hline 243.2 & 46.7 & 267.4 & 16.3 & 260.2 & 2.5 & n. inv. & & $\delta \mathrm{CCC}$ \\
\hline 336.2 & 195.9 & 196.2 & 202.4 & 184.6 & 200.7 & n. inv. & & $\tau \mathrm{O}-\mathrm{C}$ \\
\hline 393.0 & 11.1 & & & 398.9 & 0.7 & 418 & $\mathrm{mw}$ & $\delta \mathrm{OCC}$ \\
\hline & & 434.9 & 3.7 & & & & & $\gamma \mathrm{C}=\mathrm{O}$ \\
\hline & & 522.8 & 4.5 & & & & & $\delta \mathrm{OCC}$ \\
\hline & & & & 598.0 & 46.6 & 580 & $\mathrm{mw}, \mathrm{vbr}$ & $\delta \mathrm{C}=\mathrm{O}$ \\
\hline 606.8 & 23.3 & & & & & 615 & $\mathrm{~m}$ & $\delta \mathrm{C}=\mathrm{O}$ \\
\hline & & 768.9 & 0.4 & & & & & $\nu \mathrm{C}-\mathrm{C}$ \\
\hline & & & & 796.2 & 10.9 & 750 & vw & $\nu \mathrm{C}-\mathrm{C}$ \\
\hline 807.4 & 4.0 & & & & & 768 & vw & $\nu \mathrm{C}-\mathrm{C}$ \\
\hline 1092.1 & 160.8 & 1080.1 & 117.4 & 1095.6 & 127.2 & 1083 & s,br & $v \mathrm{C}-\mathrm{O}$ \\
\hline & & 1186.2 & 145.2 & & & & & $\delta \mathrm{COH}$ \\
\hline 1185.4 & 10.4 & & & 1184.7 & 69.3 & 1189 & $\mathrm{~ms}$ & $v \mathrm{C}-\mathrm{C}\left(\mathrm{H}_{3}\right)$ \\
\hline 1211.7 & 51.7 & 1228.4 & 26.8 & & & 1233 & $\mathrm{~m}$ & $\mathrm{twCH}_{2}$ \\
\hline & & & & 1220.2 & 59.2 & & & $\delta \mathrm{COH}$ \\
\hline & & & & 1254.4 & 10.8 & 1287 & $\mathrm{~m}$ & $\mathrm{twCH}_{2}$ \\
\hline & & 1265.2 & 45.6 & & & & & $v \mathrm{C}-\mathrm{C}\left(\mathrm{H}_{3}\right)$ \\
\hline 1342.7 & 5.4 & & & & & 1361 & $\mathrm{~s}$ & $\delta \mathrm{COH}$ \\
\hline 1363.7 & 74.1 & 1361.6 & 51.0 & 1360.8 & 33.6 & & & $\delta \mathrm{CH}_{3} \mathrm{~s}$ \\
\hline 1392.1 & 32.4 & 1411.5 & 20.1 & 1416.7 & 37.4 & & & $\mathrm{wCH}_{2}$ \\
\hline 1432.9 & 9.3 & 1429.2 & 26.5 & 1435.8 & 12.6 & 1422 & $\mathrm{~s}, \mathrm{br}$ & $\delta \mathrm{CH}_{3}$ as" $^{\prime \prime}$ \\
\hline 1440.2 & 22.1 & 1436.4 & 14.2 & 1450.0 & 15.2 & & & $\delta \mathrm{CH}_{3}$ as $^{\prime}$ \\
\hline 1448.4 & 13.7 & 1453.4 & 13.0 & 1459.9 & 12.9 & & & $\delta \mathrm{CH}_{2}$ \\
\hline
\end{tabular}

${ }^{a} \nu$, stretching; $\delta$, bending; r, rocking; tw, twisting; w, wagging; $\gamma$, out of plane; $\tau$, torsion; as, asymmetric; $\mathrm{s}=$ symmetric. ${ }^{b} \mathrm{n}$. inv., not investigated; experimental intensities are given in a qualitative way, the corresponding abbreviations were adopted from the original study. ${ }^{11}$

in Figure 6. The structure of such dimer was optimized within $C_{i}$ symmetry point group, and its IR spectrum is presented in Figure 5 (and in Table S5 in the Supporting Information). The appealing feature of the calculated spectrum of the dimer is the change of the vibrational frequency due to the $\delta \mathrm{COH}$ mode (compared to the monomer), resulting in the disappearance of the absorption around $1280 \mathrm{~cm}^{-1}$ (see bands marked by arrows in Figure 5C,D). The calculated spectrum of the centrosymmetric dimer (Figure 5C) is in fairly good agreement with the spectrum of the amorphous HA (Figure 5A).

The comparison of selected geometric parameters of the $\mathrm{Cc}$ conformer and the centrosymmetric dimer is presented in Table 5 (the full optimized geometry is given in Table S4 in the Supporting Information). The most important geometric difference between the monomer and the aggregate agrees with the conclusion of Jetzki et al. about the breakup of the intramolecular hydrogen bond induced by the aggregation of HA. ${ }^{12}$ The constituting unit of the dimer cannot be called a $\mathrm{Cc}$ form any more, because the $\mathrm{CCOH}$ torsional angle assumes the value of $57^{\circ}$, which is closer to a gauche rather to a cis geometry (see Table 5). Thus, in the aggregates, HA assumes a structure which does not coincide with any of the minimum-energy structures characteristic of vacuum (and reminds that found theoretically in C-PCM calculations in water environment). Moreover, according to our calculations, the intramolecular $\mathrm{H} \cdots \mathrm{O}$ distance increases from ca. $206 \mathrm{pm}$ in the Cc conformer to $262 \mathrm{pm}$ in the dimer. The intermolecular $\mathrm{H} \cdots \mathrm{O}$ distance in the dimer is ca. $190.5 \mathrm{pm}$ and evidences the formation of a new hydrogen bond. One of the most important characteristics of hydrogen bonds is their linearity, and the value of the $\mathrm{O}-\mathrm{H} \cdots \mathrm{O}$ angle also favors a much stronger hydrogen-bond interaction in the dimer $\left(164.8^{\circ}\right)$ compared with the monomer $\left(117.5^{\circ}\right)$.

In terms of the vibrational spectra, the strengthening of the hydrogen bonds manifests itself in the frequency increase related with the $\tau \mathrm{O}-\mathrm{C}$ vibrational modes. Indeed, the calculations predict an increase of this frequency from $387 \mathrm{~cm}^{-1}$ in the monomer to $546 \mathrm{~cm}^{-1}$ in the dimer (see bands marked by an asterisk in Figure 5C,D). The bands due to the torsional vibrations of protonic groups $(\mathrm{OH}, \mathrm{NH})$ involved in hydrogen bonds in crystals exhibit a strong characteristic variation of the peak intensity with the change of temperature. ${ }^{37,38}$ The absorption due to the $\tau \mathrm{O}-\mathrm{C}$ torsional mode in the spectra of $\mathrm{HA}$ crystals is also expected to follow this pattern. Such behavior was found experimentally for the band at ca. $660 \mathrm{~cm}^{-1}$ (marked by one asterisk in Figure 5B). Thus, we assign this band as being due to the $\tau \mathrm{O}-\mathrm{C}$ fundamental in the neat HA crystal. 


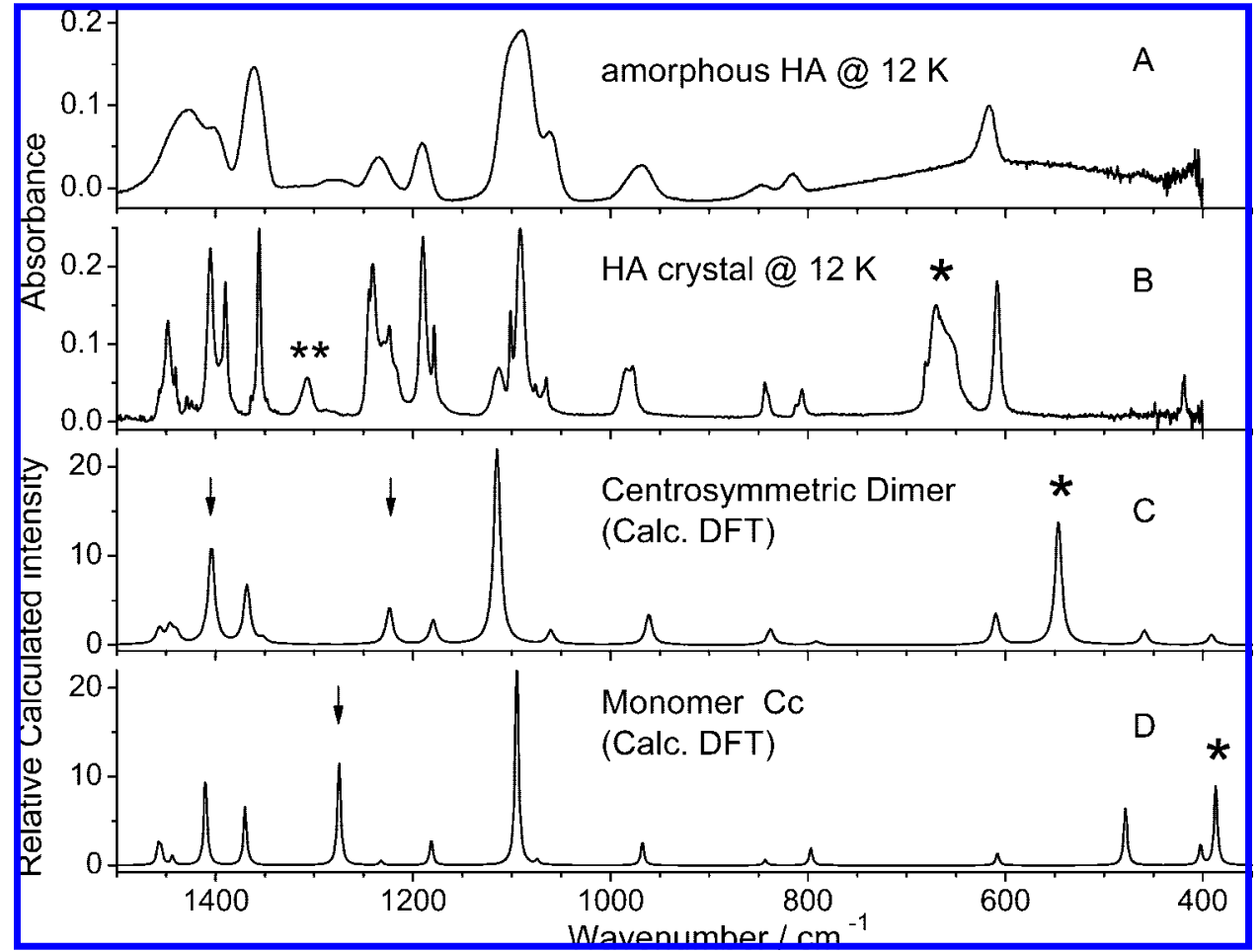

Figure 5. Experimental FTIR spectra of HA in an amorphous state (A) and in the crystal (B) at $12 \mathrm{~K}$ compared with the theoretically calculated (at the DFT(B3LYP)/6-311++G(d,p) level) IR spectra of the centrosymmetric dimer (C) and the Cc monomer (D) in vacuum. The calculated frequencies were scaled by a factor of 0.985 . The theoretical spectra were simulated by Lorentzian contours with the full width at half height equal to $8 \mathrm{~cm}^{-1}$ (dimer) and $4 \mathrm{~cm}^{-1}$ (monomer) and centered at the calculated (scaled) frequencies. In the theoretical spectra, the bands marked by arrows correspond to the modes involving the $\delta \mathrm{COH}$ coordinate, and the bands marked by one asterisk correspond to the $\tau \mathrm{O}-\mathrm{C}$ fundamental. The bands marked by one and two asterisks in the experimental spectrum of the crystal were assigned to the $\tau \mathrm{O}-\mathrm{C}$ fundamental and to its first overtone, respectively.

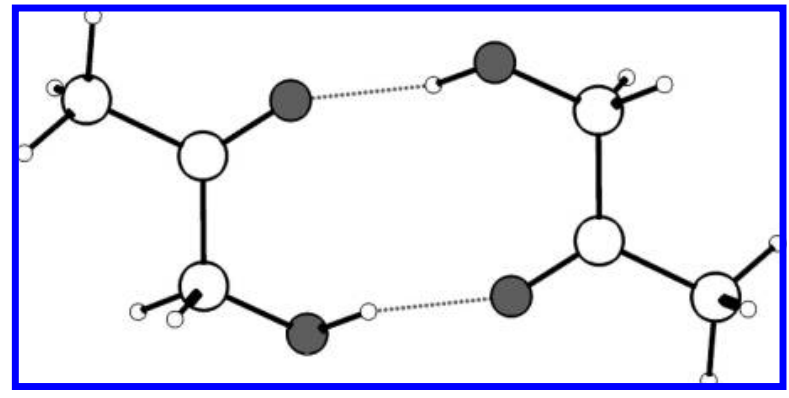

Figure 6. Optimized structure (calculation at the DFT(B3LYP)/6$311++\mathrm{G}(\mathrm{d}, \mathrm{p})$ level) of the centrosymmetric dimer of HA. Oxygen atoms are gray. For comparison of the geometric parameters of the monomer (Cc conformer) and the dimer, see Table 5.

This position of the fundamental vibration then suggests the assignment of the band at $1308 \mathrm{~cm}^{-1}$ (marked by two asterisks in Figure 5B) to its first overtone. This is consistent with the harmonic calculations of the vibrational spectrum of the dimer, which do not predict any vibration in this region of the spectrum. The band assigned to the overtone, similarly to the fundamental, also exhibits a strong variation in its intensity as a function of the sample temperature, thus justifying the assignment to the protonic mode. Further proof for the assignments of the two bands at 660 and $1308 \mathrm{~cm}^{-1}$ to the protonic modes of the aggregate follows from the spectrum of the amorphous sample. Indeed, in the absence of the orientational order, systematic formation of the centrosymmetric dimers is unlikely, and the two bands in question disappear from the experimental spectrum (see Figure 5A).

The assumption of the centrosymmetric dimer as the main structural motif of HA crystals, although allowing to explain
TABLE 5: Selected Geometrical Parameters for the Cc Conformer of HA Molecule Compared with that of the Centrosymmetric Dimer Optimized at the DFT/

6-311 $++\mathbf{G}(\mathbf{d}, \mathbf{p})$ Level of Theory (for Isolated Molecules in Vacuum)

\begin{tabular}{lcr}
\hline \multicolumn{1}{c}{ parameter $^{a}$} & monomer $^{b}$ & dimer $^{b}$ \\
\hline & Bond (pm) & \\
$\mathrm{C}=\mathrm{O}$ & 121.39 & 121.45 \\
$\mathrm{C}-\mathrm{C}(=\mathrm{O})$ & 152.07 & 152.29 \\
$\mathrm{C}-\mathrm{O}$ & 140.19 & 139.46 \\
$\mathrm{O}-\mathrm{H}$ & 97.07 & 97.11 \\
$\mathrm{H} \cdots \mathrm{O}$ (in) & 206.44 & 262.41 \\
$\mathrm{H} \cdots \mathrm{O}$ (out) & dne & 190.52 \\
& Angle (degree) & \\
$\mathrm{O}=\mathrm{C}-\mathrm{C}$ & 119.29 & 121.85 \\
$\mathrm{C}-\mathrm{C}-\mathrm{O}$ & 112.16 & 115.35 \\
$\mathrm{C}-\mathrm{O}-\mathrm{H}$ & 106.16 & 110.41 \\
$\mathrm{O}-\mathrm{H} \cdots \mathrm{O}$ (in) & 117.46 & 89.50 \\
$\mathrm{O}-\mathrm{H} \cdots \mathrm{O}$ (out) & dne & 164.79 \\
& 3.93 & \\
$\mathrm{O}=\mathrm{C}-\mathrm{C}-\mathrm{O}$ & -4.42 & -16.68 \\
$\mathrm{C}-\mathrm{C}-\mathrm{O}-\mathrm{H}$ & 3.42 & 57.01 \\
$\mathrm{C}-\mathrm{O}-\mathrm{H} \cdots \mathrm{O}$ & -1.33 & -44.34 \\
$\mathrm{O}-\mathrm{H} \cdots \mathrm{O}=\mathrm{C}$ & & 35.95
\end{tabular}

${ }^{a}$ in, intramolecular parameter in both monomer and dimer; out, intermolecular parameter in dimer; dne, does not exist. ${ }^{b}$ See Figure 1 for the structure of $\mathrm{Cc}$ monomer, Figure 6 for the structure of the dimer, Table S1 in the Supporting Information for the complete optimized geometry of $\mathrm{Cc}$ monomer, and Table S4 in the Supporting Information for the complete optimized geometry of the dimer.

the experimental spectra, still should be considered with some reservation. The vibrational frequency of the $\tau \mathrm{O}-\mathrm{C}$ fundamental 
is predicted ca. $100 \mathrm{~cm}^{-1}$ lower than the observed one, which can be attributed either to the limitations of the theoretical method used or to the wrong model. Alternative structures of the hydrogen-bonded aggregates of HA, consisting of exclusively Cc monomers, are possible (for example, chain-like aggregates), but their theoretical simulation is a nontrivial task. The main structural motif of the chain is an open dimer with one intermolecular hydrogen bond connecting two Cc monomers. The theoretical optimizations of such open dimers resulted, however, in structures with much higher relative energies or converged to the centrosymmetric dimer. At present, it seems to us that the centrosymmetric dimer (based on the $\mathrm{Cc}$ conformer) is the most plausible structure for HA in the neat crystal.

4.5. NMR Spectra in Water and Chloroform Solution. Glushonok et al. ${ }^{14}$ reported an NMR study of HA in both water and chloroform solutions, concluding that HA exists essentially in the monomeric form in these solutions and measuring the chemical shifts for ${ }^{1} \mathrm{H}$ and ${ }^{13} \mathrm{C}$ nuclei. In the present investigation, we calculated these chemical shifts (and also those for ${ }^{17} \mathrm{O}$ ) in both previously investigated solvents. ${ }^{14}$ Because both in water and in chloroform, the estimated population of the $\mathrm{Cc}$ conformer is strongly dominant (over 80 and $90 \%$, respectively; see Table 2), the chemical shifts were calculated for this conformer. Three different levels of theory were used [MP2, DFT/B3LYP, and DFT/BP86 methods with the 6-311++G(d,p) basis set and the C-PCM model]. Spectra for the reference systems, tetramethylsilane, and $\mathrm{H}_{2} \mathrm{O}$ were also calculated by using the same methods. The results are summarized in Table 6. For ${ }^{1} \mathrm{H}$ and ${ }^{13} \mathrm{C}$, the relative performance of calculations at different levels shows that (i) in general, all the methods predict the chemical shifts quite well, the DFT methods estimating better the ${ }^{1} \mathrm{H}$ chemical shifts (average relative error $10 \%$ for MP2 versus $6 \%$ for DFT), whereas the MP2 method predicts the ${ }^{13} \mathrm{C}$ chemical shifts slightly better $(2.5 \%$ versus $6 \%)$, (ii) the two DFT methods predict equally well the chemical shifts for ${ }^{1} \mathrm{H}$ and ${ }^{13} \mathrm{C}$, with average relative errors of ca. $6 \%$, (iii) the ${ }^{13} \mathrm{C}$ chemical shifts are estimated with some average relative error by all methods in water and chloroform $(2-3 \%$ for MP2 and $6 \%$ for both DFT methods), and (iv) for ${ }^{1} \mathrm{H}$ chemical shifts, the general trend is that of a better performance of the theoretical methods when the solvent is chloroform (the BP86 provides estimations with equal average relative error in both solvents). On the whole, the various methods used all appear to be able to provide good theoretical estimations of the chemical shifts for both ${ }^{1} \mathrm{H}$ and ${ }^{13} \mathrm{C}$.

\section{Conclusion}

Matrix-isolation experimental investigation of spectra and structure of monomeric HA has been carried out, according to our knowledge, for the first time. In addition, solid-state spectra of the compound were also studied in a wide temperature range (from 12 to $175 \mathrm{~K}$ ). Detailed theoretical calculations were carried out to facilitate the interpretation of the vibrational IR spectra of the compound and to understand the conformational isomerism.

PES calculated at the MP2/6-311++G(d,p) level of theory revealed the existence of four minima $(\mathrm{Cc}, \mathrm{Tt}, \mathrm{Tg}$, and $\mathrm{Ct}$ ), with the $\mathrm{Cc}$ form being the most stable one, owing to the presence of an intramolecular hydrogen bond. The remaining forms are not stabilized by such interaction; their relative energies were calculated to be above $11 \mathrm{~kJ} \mathrm{~mol}^{-1}$, and their equilibrium populations at room temperature are less than $1 \%$. In agreement with the calculations, only the main form (Cc) was identified
TABLE 6: Experimental and Computed Chemical Shifts for the Cc Conformer of $\mathrm{HA}^{a}$

\begin{tabular}{|c|c|c|c|c|}
\hline \multicolumn{5}{|c|}{ Solvent $=$ Chloroform } \\
\hline & exptl. ${ }^{14}$ & MP2 & B3LYP & BP86 \\
\hline \multicolumn{5}{|c|}{$\delta_{\mathrm{H}}(\mathrm{ppm})$} \\
\hline $\mathrm{H}_{5}$ & 2.09 & 2.16 & 1.96 & 2.04 \\
\hline $\mathrm{H}_{6}$ & 2.09 & 1.75 & 1.99 & 2.02 \\
\hline $\mathrm{H}_{7}$ & 2.09 & 1.96 & 2.10 & 2.12 \\
\hline $\mathrm{H}_{8}$ & 4.19 & 3.97 & 4.39 & 4.57 \\
\hline $\mathrm{H}_{9}$ & 4.19 & 3.59 & 4.21 & 4.41 \\
\hline $\mathrm{H}_{11}$ & 3.27 & $\begin{array}{l}2.37 \\
(12 \%)\end{array}$ & $\begin{array}{l}2.10 \\
(9 \%)\end{array}$ & $\begin{array}{l}2.71 \\
(6 \%)\end{array}$ \\
\hline $\begin{array}{l}\mathrm{C}_{1} \\
\mathrm{C}_{2} \\
\mathrm{C}_{4}\end{array}$ & $\begin{array}{r}67.00 \\
210.05 \\
25.00\end{array}$ & $\begin{array}{l}\delta_{\mathrm{C}}(\mathrm{pp} \\
65.28 \\
217.64 \\
25.50 \\
(3 \%)\end{array}$ & $\begin{array}{l}74.04 \\
217.00 \\
26.17 \\
(6 \%)\end{array}$ & $\begin{array}{l}75.39 \\
214.94 \\
25.50 \\
(6 \%)\end{array}$ \\
\hline $\begin{array}{r}\mathrm{O}_{3} \\
\mathrm{O}_{10}\end{array}$ & & $\begin{array}{l}\delta_{\mathrm{O}}(\mathrm{pp} \\
645.58 \\
21.54\end{array}$ & $\begin{array}{l}618.37 \\
17.91\end{array}$ & $\begin{array}{l}593.60 \\
17.46\end{array}$ \\
\hline \multicolumn{5}{|c|}{ Solvent $=$ Water } \\
\hline & exptl. ${ }^{14}$ & MP2 & B3LYP & BP86 \\
\hline \multicolumn{5}{|c|}{$\delta_{\mathrm{H}}(\mathrm{ppm})$} \\
\hline $\mathrm{H}_{5}$ & 1.92 & 2.16 & 1.92 & 1.88 \\
\hline $\mathrm{H}_{6}$ & 1.92 & 1.75 & 1.99 & 2.00 \\
\hline $\mathrm{H}_{7}$ & 1.92 & 1.96 & 2.08 & 2.13 \\
\hline $\mathrm{H}_{8}$ & 4.15 & 3.97 & 4.34 & 4.45 \\
\hline $\mathrm{H}_{9}$ & 4.15 & 3.59 & 4.20 & 4.37 \\
\hline $\mathrm{H}_{11}$ & & $\begin{array}{l}2.25 \\
(8 \%)\end{array}$ & $\begin{array}{l}1.77 \\
(4 \%)\end{array}$ & $\begin{array}{l}1.81 \\
(6 \%)\end{array}$ \\
\hline \multicolumn{5}{|c|}{$\delta_{\mathrm{C}}(\mathrm{ppm})$} \\
\hline $\mathrm{C}_{1}$ & 66.50 & 65.55 & 74.04 & 76.07 \\
\hline $\mathrm{C}_{2}$ & 212.45 & 217.50 & 217.00 & 215.62 \\
\hline $\mathrm{C}_{4}$ & 24.80 & $\begin{array}{l}25.00 \\
(2 \%)\end{array}$ & $\begin{array}{l}26.17 \\
(6 \%)\end{array}$ & $\begin{array}{l}25.20 \\
(6 \%)\end{array}$ \\
\hline \multicolumn{5}{|c|}{$\delta_{\mathrm{O}}(\mathrm{ppm})$} \\
\hline $\mathrm{O}_{3}$ & & 655.37 & 632.88 & 623.81 \\
\hline $\mathrm{O}_{10}$ & & 25.00 & 26.98 & 32.43 \\
\hline
\end{tabular}

${ }^{a}$ See Figure 1 for atom numbering. The values in parentheses correspond to relative errors $\left\{\left[\sum_{n}\left|\left(\delta_{\text {cal }}-\delta_{\text {exp }}\right) / \delta_{\text {exp }}\right|\right] / n\right\}$ in the predicted chemical shifts for ${ }^{1} \mathrm{H}$ or ${ }^{13} \mathrm{C}$.

in the spectrum of the matrix-isolated compound. A comparison of the experimental and the theoretical spectra of the $\mathrm{Cc}$ conformer shows a good overall agreement.

The solid-state spectra of HA were recorded for the amorphous compound as well as for the crystal. Comparison of these spectra with the spectrum of matrix-isolated HA indicated that the bands due to the skeletal vibrations are similar in all cases, whereas the bands originating in protonic modes are different. The experimental spectra of solids showed no absorptions due to minor conformers of $\mathrm{HA}(\mathrm{Tt}, \mathrm{Tg}$, and $\mathrm{Ct}$ ). At the same time, the spectra of solids were not completely compatible with the spectra of the main Cc conformer (in the matrix), indicating disruption of the intramolecular hydrogen bond in this form in the crystal.

To provide an explanation to these observations and to understand the structural and spectral features of solid HA, structures of different aggregates based on two Cc units were optimized, and their IR spectra were theoretically simulated. A plausible explanation of the experimental spectra could be given on the basis of a centrosymmetric dimer of HA as the main structural motif of the crystal. A comparison of the calculated 
spectrum of the dimer with that of the monomer could successfully explain the frequency shifts experimentally observed for the protonic modes of the compound. We predict that upon crystallization, the intramolecular hydrogen bond characteristic of monomers converts into an intermolecular hydrogen bond characteristic of aggregates of HA.

Calculations carried out for the HA conformers in water solution revealed that only two minor conformers ( $\mathrm{Tt}$ and $\mathrm{Ct}$ ) are stabilized in this environment. Their calculated relative energies decrease down to $4-6 \mathrm{~kJ} \mathrm{~mol}^{-1}$ with respect to the main $\mathrm{Cc}$ form. Spectra calculated in the present study for $\mathrm{Cc}$, $\mathrm{Ct}$, and $\mathrm{Tt}$ conformers in water solution were successfully compared with the experimental spectra reported previously.

Finally, NMR chemical shifts for ${ }^{1} \mathrm{H},{ }^{13} \mathrm{C}$, and ${ }^{17} \mathrm{O}$ were calculated by using different approaches [MP2, DFT(B3LYP) and DFT(BP86)]. Their comparison with the available experimental data shows a good agreement.

Acknowledgment. This work was supported by the Portuguese Science Foundation (FCT) Grant no. SFRH/BPD/31840/ 2006 and Research Projects POCI/QUI/58937/2004 and POCI/ QUI/59019/2004.

Supporting Information Available: Table S1, optimized geometrical parameters for the different minima of HA calculated at the MP2/6-311++G(d,p) and DFT/6-311++G(d,p) levels of theory (isolated molecule in vacuum); Table S2, MP2/ $6-311++\mathrm{G}(\mathrm{d}, \mathrm{p})$ and DFT/6-311++G(d,p) calculated frequencies and IR intensities for the higher-energy minima of HA (isolated molecule in vacuum); Table S3, MP2/6-311++G(d,p) and DFT/6-311++G(d,p) calculated frequencies and IR intensities for $\mathrm{Cc}$, Tt, and $\mathrm{Ct}$ energy minima of $\mathrm{HA}$ in water solution (C-PCM calculation); Table S4, geometrical parameters for HA centrosymmetric dimer calculated at the DFT(B3LYP)/6$311++\mathrm{G}(\mathrm{d}, \mathrm{p})$ level; Table S5, vibrational frequencies and IR intensities for the centrosymmetric HA dimer calculated at the DFT(B3LYP)/6-311++G(d,p) level; Figure S1, MP2/6$311++\mathrm{G}(\mathrm{d}, \mathrm{p})$ calculated IR spectra for minimum-energy structures of HA (isolated molecule in vacuum). This material is available free of charge via the Internet at http://pubs.acs.org.

Note Added in Proof. In a recent theoretical study, Jalbout et al. ${ }^{39}$ explored torsional potentials for HA momomer and found that the PES contains four minimum structures and some of these species have the zero-point energies higher than the barriers of rotation, in full agreement with the present study. Moreover, the study of dual methyl and $\mathrm{OH}$ rotation PES showed that the reduced barrier to methyl rotation can lead to several rotamers. ${ }^{39}$

\section{References and Notes}

(1) Dillon, T. J.; Horowitz, A.; Hölscher, D.; Crowley, J. N.; Vereecken, L.; Peeters, J. Phvs. Chem. Chem. Phvs. 2006, 8, 236.

(2) Galano, A. J. Phys. Chem. A 2006, 110, 9153.

(3) Wu, Y.; Xie, D. Q.; Xue, Y. J. Comput. Chem. 2003, 24, 931.

(4) Grosjean, D.; Williams, E. L., II.; Grosjean, E. Environ. Sci. Technol. 1993, 27, 830.

(5) Orlando, J. J.; Tyndall, G. S.; Fracheboud, J. M.; Estupiñan, E. G.; Haberkorn, S.; Zimmer, A. Atmos. Environ. 1999, 33, 1621.

(6) Chowdhury, P. K.; Upadhyaya, H. P.; Naik, P. D.; Mittal, J. P. Chem. Phvs. Lett. 2002, 356, 476.
(7) Pakarinen, J. M. H.; Vainiotalo, P.; Pakkanen, T. A.; Kenttämaa, H. I. J. Am. Chem. Soc. 1993, 115, 12431.

(8) Kroll, J. H.; Ng, N. L.; Murphy, S. M.; Varutbangkul, V.; Flagan, R. C.; Seinfeld, J. H. J. Geophys. Res., [Atmos.] 2005, 110. 443.

(9) Kattija-Ari, M.; Harmony, M. D. Int. J. Quantum Chem. 1980, 17,

(10) Apponi, A. J.; Hoy, J. J.; Halfen, D. T.; Ziurys, L. M.; Brewster, M. A. Astrophvs. J. 2006, 652, 1787.

(11) Mohaček-Grošev, V. Spectrochim. Acta A 2005, 61, 477.

(12) Jetzki, M.; Luckhaus, D.; Signorell, R. Can. J. Chem. 2004, 82, 915.

(13) Espinosa-García, J.; Dóbé, S. THEOCHEM 2005, 713, 119.

(14) Glushonok, G. K.; Glushonok, T. G.; Maslovskaya, L. A.; Shadyro, O. I. Russ. J. Gen. Chem. 2003, 73, 1027.

(15) Boykin, D. W.; Baumstark, A. L. In 170 NMR Spectroscopy in Organic Chemistry; Boykin, D. W., Ed.; CRC Press: Boca Raton, FL, 1990.

(16) Frisch, M. J.; Head-Gordon, M.; Pople, J. A. Chem. Phvs. Lett. 1990, 166, 281.

(17) Becke, A. D. Phys. Rev. A 1988, 38, 3098

(18) Lee, C. T.; Yang, W. T.; Parr, R. G. Phvs. Rev. B 1988, 37, 785.

(19) Vosko, S. H.; Wilk, L.; Nusair, M. Can. J. Phvs. 1980, 58, 1200.

(20) Schahtschneider, J. H.; Mortimer, F. S. Vibrational Analysis of Polyatomic Molecules. VI. FORTRAN IV Programs for Solving the Vibrational Secular Equation and for the Least-Squares Refinement of Force Constants. Project No. 31450. Structural Interpretation of Spectra; Shell Development Co.: Emeryville, CA, 1969.

(21) Pulay, P.; Fogarasi, G.; Pang, F.; Boggs, J. E. J. Am. Chem. Soc. 1979, 101, 2550.

(22) Keresztury, G.; Jalsovszky, G. J. Mol. Struct. 1971, 10, 304.

(23) Cossi, M.; Scalmani, G.; Rega, N.; Barone, V. J. Chem. Phvs. 2002, $117,43$.

(24) Cossi, M.; Rega, N.; Scalmani, G.; Barone, V. J. Comput. Chem. 2003, 24, 669.

(25) Perdew, J. P. Phys. Rev. B 1986, 33, 8822.

(26) Frisch, M. J.; Trucks, G. W.; Schlegel, H. B.; Scuseria, G. E.; Robb, M. A.; Cheeseman, J. R.; Montgomery, J. A., Jr.; Vreven, T.; Kudin, K. N.; Burant, J. C.; Millam, J. M.; Iyengar, S. S.; Tomasi, J.; Barone, V.; Mennucci, B.; Cossi, M.; Scalmani, G.; Rega, N.; Petersson, G. A.; Nakatsuji, H.; Hada, M.; Ehara, M.; Toyota, K.; Fukuda, R.; Hasegawa, J.; Ishida, M.; Nakajima, T.; Honda, Y.; Kitao, O.; Nakai, H.; Klene, M.; Li, X.; Knox, J. E.; Hratchian, H. P.; Cross, J. B.; Bakken, V.; Adamo, C.; Jaramillo, J.; Gomperts, R.; Stratmann, R. E.; Yazyev, O.; Austin, A. J.; Cammi, R.; Pomelli, C.; Ochterski, J. W.; Ayala, P. Y.; Morokuma, K.; Voth, G. A.; Salvador, P.; Dannenberg, J. J.; Zakrzewski, V. G.; Dapprich, S.; Daniels, A. D.; Strain, M. C.; Farkas, O.; Malick, D. K.; Rabuck, A. D.; Raghavachari, K.; Foresman, J. B.; Ortiz, J. V.; Cui, Q.; Baboul, A. G.; Clifford, S.; Cioslowski, J.; Stefanov, B. B.; Liu, G.; Liashenko, A.; Piskorz, P.; Komaromi, I.; Martin, R. L.; Fox, D. J.; Keith, T.; Al-Laham, M. A.; Peng, C. Y.; Nanayakkara, A.; Challacombe, M.; Gill, P. M. W.; Johnson, B.; Chen, W.; Wong, M. W.; Gonzalez, C.; Pople, J. A. Gaussian 03, revision C.02; Gaussian, Inc.: Wallingford, CT, 2004.

(27) Reva, I. D.; Stepanian, S. G.; Adamowicz, L.; Fausto, R. Chem. Phvs. Lett. 2003, 374, 631.

(28) Borba, A.; Gómes-Zavaglia, A.; Simões, P. N. N. L.; Fausto, R. J. Phvs. Chem. A 2005, 109, 3578.

(29) Maçôas, E. M. S.; Khriachtchev, L.; Pettersson, M.; Fausto, R.; Räsänen, M. J. Am. Chem. Soc. 2003, 125, 16188.

(30) Maçôa, E. M. S.; Khriachtchev, L.; Pettersson, M.; Fausto, R.; Räsänen, M. J. Chem. Phvs. 2004, 121, 1331.

(31) Reva, I. D.; Jarmelo, S.; Lapinski, L.; Fausto, R. J. Phvs. Chem. A 2004, 108, 6982

(32) Maçôas, E. M. S.; Khriachtchev, L.; Pettersson, M.; Fausto, R.; Räsänen, M. Phvs. Chem. Chem. Phvs. 2005, 7, 743.

(33) Maçôas, E. M. S.; Khriachtchev, L.; Pettersson, M.; Fausto, R.; Räsänen, M. J. Phvs. Chem. A 2005, 109, 3617.

(34) Maçôa, E. M. S.; Khriachtchev, L.; Pettersson, M.; Lundell, J.; Fausto, R.; Räsänen, M. Vib. Spectrosc. 2004, 34, 73.

(35) Bondybey, V. E. Annu. Rev. Phvs. Chem. 1984, 35, 591.

(36) Maçôas, E. M. S.; Khriachtchev, L.; Pettersson, M.; Juselius, J.; Fausto, R.; Räsänen, M. J. Chem. Phvs. 2003, 119, 11765.

(37) Rozenberg, M.; Shoham, G.; Reva, I.; Fausto, R. Spectrochim. Acta A 2003, 59, 3253 .

(38) Jarmelo, S.; Reva, I.; Carey, P. R.; Fausto, R. Vib. Spectrosc. 2007, 43,395 .

(39) Jalbout, A. F.; Contreras-Torres, F. F.; Adamowicz, L. Int. J. Ouantum Chem. 2008, 108, 279.

JP8012909 